This item was submitted to Loughborough's Research Repository by the author.

Items in Figshare are protected by copyright, with all rights reserved, unless otherwise indicated.

\title{
The effects of scale and process parameters in cake filtration
}

PLEASE CITE THE PUBLISHED VERSION

PUBLISHER

Elsevier / @ Institution of Chemical Engineers

VERSION

AM (Accepted Manuscript)

LICENCE

CC BY-NC-ND 4.0

REPOSITORY RECORD

Tarleton, E.S., and S.A. Willmer. 2009. "The Effects of Scale and Process Parameters in Cake Filtration". figshare. https://hdl.handle.net/2134/4916. 
This item was submitted to Loughborough's Institutional Repository (https://dspace.lboro.ac.uk/) by the author and is made available under the following Creative Commons Licence conditions.

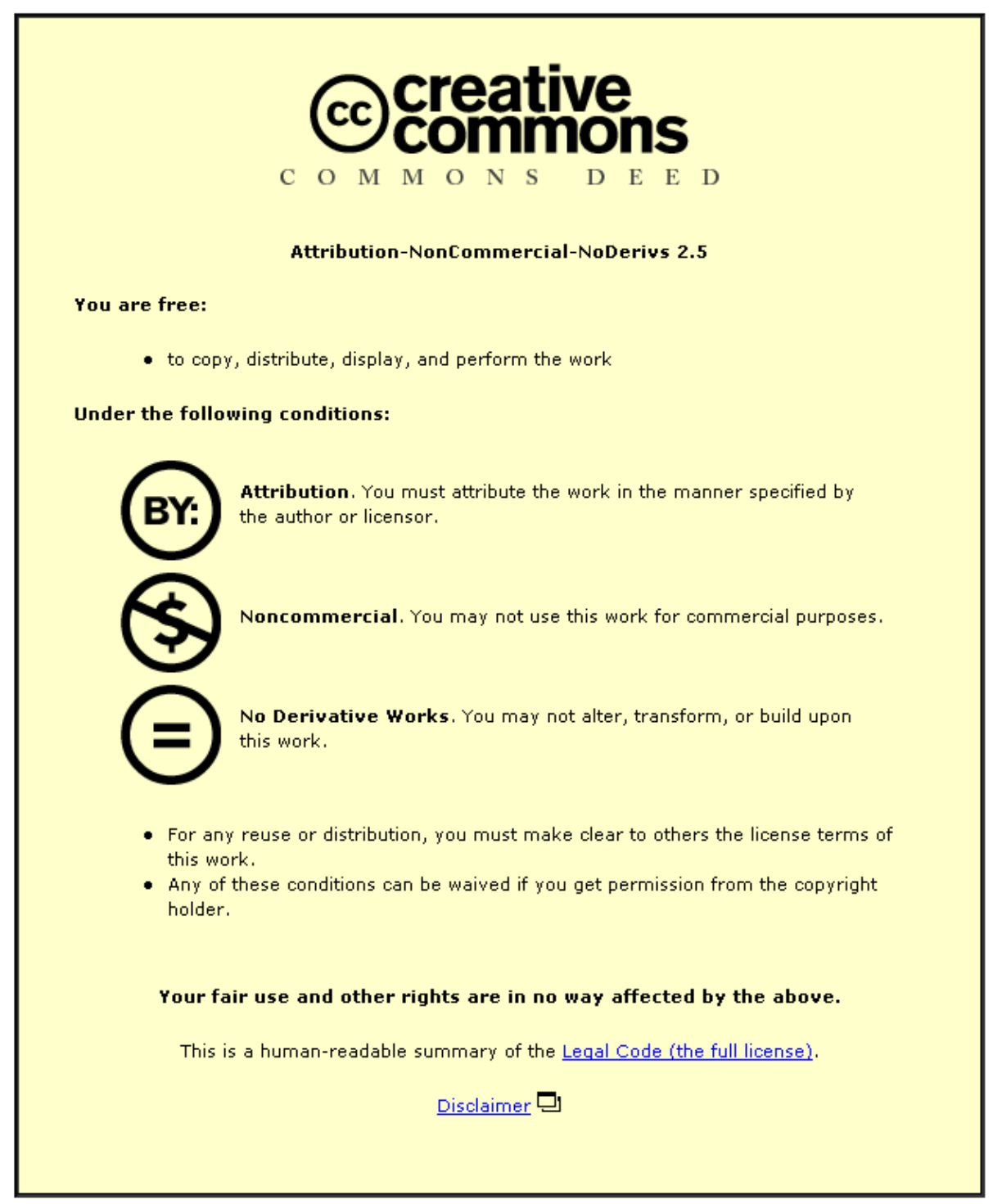

For the full text of this licence, please go to: http://creativecommons.org/licenses/by-nc-nd/2.5/ 


\title{
THE EFFECTS OF SCALE AND PROCESS PARAMETERS IN CAKE FILTRATION
}

\author{
E.S. Tarleton (e.s.tarleton@lboro.ac.uk) and S.A. Willmer \\ Department of Chemical Engineering, Loughborough University, Loughborough, Leics. LE11 3TU, \\ UK.
}

\begin{abstract}
A well controlled and instrumented apparatus has been used for a systematic investigation of cake growth in pressure leaf filtration. Both incompressible and compressible systems have been filtered over a range of constant pressures to evaluate the effects of applied pressure, initial suspension concentration, time of filtration, particle surface charge (interpreted through suspension $\mathrm{pH}$ ) and scale of filtration. Sample data show how aqueous calcite and zinc sulphide systems behave in different manners dependent on both the relative magnitudes of the process parameters and apparently on the scale at which a filtration is performed. The data, analysed by consistent procedures through the general filtration equation, indicate that the scale-up 'constants' frequently used in filter design may vary with scale and how variations in measured cake properties can be seen as scale is altered. The results are discussed in the context of filter design.
\end{abstract}

\section{KEYWORDS}

Cake filtration; Compressibility; Scale-up; Filter design; Process parameters

\section{INTRODUCTION}

The use of cake filtration is widespread in many of the chemical, food, brewing, ceramic and mineral processing industries. Within these areas the objective of filtration may be to recover a clear filtrate, to recover the suspended solids, or, in some cases, to recover both the solids and the filtrate. Referring to Figure 1, these operations are achieved by imposing a pressure gradient across a semi-permeable medium such that particulate material is separated from a suspending fluid to produce a cake upon the filtering surface and a clear filtrate downstream of the septum. The suspension is fed toward the filter medium where permeable layers of particulates form initial layers, effectively filtering the remaining suspension as the cake grows with time. The flow of liquid through the filter cake induces viscous drag forces on the constituent particles that arise from the interfacial transfer of momentum from the liquid to the solid particles. If the cake structure is able to withstand the cumulative effect of these forces throughout a filtration to give a uniform and timeindependent cake porosity, then the cake is regarded as incompressible. Otherwise, particle rearrangement occurs to induce a porosity gradient through the cake height and the cake is thus considered to be compressible; the maximum solids concentration generally occurring at the cake/filter medium interface.

Despite the importance of cake filtration to many industries, and the relative wealth of research in the subject area, there is still much reliance on heuristics and conventional (or classical) cake filtration theory ${ }^{1,2}$ to analyse and scale-up filtration operations. Ruth ${ }^{2}$ showed that the resistance of a cake formed during filtration is proportional to the amount of cake deposited at the filter medium provided cake porosity and filtration pressure are assumed constant. This principle, which infers that conventional theory is only valid when a cake is incompressible, is manifested in the now widely used general filtration equation. Grace ${ }^{3}$ apparently validated Ruth's work using compression permeability (C-P) cells through the so called 'perfect parabolas' for volume-time discharge curves. Tiller ${ }^{4}$ later showed that the discharge curves for constant pressure filtrations were not always 'perfect parabolas' but that cake resistance was seemingly dependent on a host of process parameters. Since the work of Ruth, many workers (including Tiller) have examined 
compressibility and found cake resistance and cake solids concentration to be functions of time of filtration $^{5-7}$, suspension concentration ${ }^{5,8,9}$, particle size distribution ${ }^{3,10-13}$, particle shape and morphology ${ }^{3,5,10}$, particle surface charge ${ }^{11,14-16}$, the deposition of fine particles in interstices ${ }^{5,17,18}$ and the characteristics of the filter medium ${ }^{19,20}$. The apparent complexity of the interactions between these parameters has hampered research in solid/liquid separation for some time and led many workers toward the use of empiricism and heuristics in filter design and operation, rather than developing models from first principles.

In an effort to amend conventional theory to account for compressibility the general filtration equation has previously been modified to include the concept of average values for specific cake resistance $(\alpha)$ and effective feed concentration $(c)^{21}$ such that

$$
t=\frac{\mu \alpha_{a v} c}{2 A^{2} \Delta P} V^{2}+\frac{\mu R_{m}}{A \Delta p} V
$$

where $t$ is the time, $V$ the cumulative volume, $\mu$ the dynamic viscosity of filtrate, $A$ the filter area, $\Delta P$ the filtration pressure and $R_{m}$ the filter medium resistance. For filter design the use of scale-up constants in eqn. (1) is widespread where sequences of tests at different constant pressures are performed using either a C-P cell ${ }^{2,3,22}$, piston press ${ }^{11}$ or leaf filter ${ }^{23-29}$ to evaluate the four scale-up constants $\alpha_{0}, n, C_{0}$ and $m$ required to characterise the filtration properties of a feed through

$$
\begin{aligned}
& \alpha_{a v}=\alpha_{0}(1-n) \Delta P_{c}^{n} \\
& C_{a v}=C_{0} \Delta P_{c}^{m}
\end{aligned}
$$

where $C$ is the cake solids volume fraction and related to $c^{21}$. The four scale-up constants shown in eqns. (2) \& (3) are also used in 'modern' filtration theory ${ }^{4,30-32}$ where force-momentum balances are derived to provide more detail of cake formation. Although this supposedly more advanced theory has struggled to find use outside of academia, it does provide a method of predicting solids concentration profiles in a growing cake provided the filtrate flow rate and scale-up constants are known. Whilst the problems associated with determining scale-up constants using C-P cells are well documented ${ }^{33-37}$, there is little or no proof in the research literature that the scale-up constants are in fact constant and thus scale independent. Indeed, some doubt must be cast on the assumption when consideration is given to experienced industrialists who design pressure filters using a minimum 'rule-of-thumb' safety margin of $25 \%$ on filter area ${ }^{38}$.

It is apparent that cake filtration has been the subject of relatively intensive investigation since at least the early 1900's. Although the filtration behaviour of both incompressible and compressible cakes is now more fully understood there still remain many fundamental issues of difficulty. The work presented in this paper describes some of the results from an integrated program of research into pressure driven cake filtration. Data from a well controlled filtration apparatus are shown which highlight the influence of a range of process parameters including the scale of filtration.

\section{EXPERIMENTAL APPARATUS AND CHARACTERISATION}

The pressure filtration apparatus used in the research program is shown schematically in Figure 2. It comprised of $5 \mathrm{I}$ and $20 \mathrm{I}$ stirred storage vessels fabricated from $316 \mathrm{~L}$ grade stainless steel (s/s) to $\mathrm{BS} 5500^{39}$. Situated downstream of these two vessels, used to contain feed suspension, was one of the four interchangeable leaf filter cells associated with the apparatus. These dead-end pressure filter cells, also fabricated from $316 \mathrm{~L} \mathrm{~s} / \mathrm{s}$, respectively had filtering areas of $5,23,170$ \& $490 \mathrm{~cm}^{2}$ and each incorporated identical suspension distributor plates in addition to thirty pairs of diametrically opposed s/s electrodes positioned at $5 \mathrm{~mm}$ vertical spacings above the septum. The electrodes were used to obtain resistance measurements and subsequently solids concentration 
profiles within a filtering suspension or cake through a well established technique ${ }^{26}$. The three larger filter cells and both feed vessels had water jackets fitted such that a constant temperature heating/cooling circuit circulated water through their jackets to eliminate transient temperature effects. The storage vessels and filter cells were connected together via s/s piping and pneumatically operated ball valves. An electronic air regulator was used to control the filtration pressure between 0 and $8 \times 10^{5} \mathrm{~Pa}$ as supplied by a dedicated air compressor. Piezo-electric pressure transducers situated on the feed air line of the storage vessels and on the filtrate line respectively monitored the pressures upstream and downstream of the fitted filter cell and allowed a constant pressure gradient to be maintained across the cell. The flow of filtrate during an experiment was monitored via an interfaced electronic balance or flow meter. All the sequencing and measurement operations of the apparatus were automatically performed via computer, electronic circuitry and dedicated software. The data obtained from the constant pressure experiments, including filtrate flow rate, time of filtration, electrical resistance measurements, filtration conditions etc. were displayed in real time on the computer screen throughout a test and also saved to disk files for subsequent processing ${ }^{40}$.

In order to interpret the filtration data it was necessary to identify and characterise suitable feed suspensions and a filter medium. The particulate materials chosen were characterised with respect to their particle size, size distribution, shape and surface charge. Calcite $\left(\mathrm{CaCO}_{3}\right)$, grade BP/EP manufactured by Pumex Ltd. ${ }^{\text {TM }}$, and zinc sulphide $(Z n S)$, grade $L$ manufactured by Sachtleben Chemie ${ }^{\mathrm{TM}}$, were identified as being representative of incompressible and compressible systems respectively ${ }^{\dagger}$. Each feed suspension was prepared by dispersing the dry powder in distilled water through gentle agitation. The zinc sulphide suspensions were stabilised with the addition of an anionic dispersant (supplied by Allied Colloids Ltd. ${ }^{\mathrm{TM}}$ ) at a dosing of $0.1 \%$ dry Dispex $\mathrm{N} 40$ on dry zinc sulphide powder and $\mathrm{pH}$ adjusted by the addition of analar glacial acetic acid or sodium hydroxide. Table 1 shows the relevant particle size data. SEM's of the calcite and zinc sulphide powders showed a rhomboidal shape and a near spherical, oblate ellipsoid, shape respectively. Due to the inherent difficulties of determining the ionic strength of suspensions (particularly in the presence of Dispex) the influence of particle surface charge was interpreted solely through suspension $\mathrm{pH}$. Figure 3 shows the $\zeta$-potential-pH relationship for both the calcite and zinc sulphide suspensions in distilled water. For calcite only a small variation in $\zeta$-potential was observed as the $\mathrm{pH}$ was changed from $\mathrm{pH}=9.0$ to $\mathrm{pH}=12$ by the addition of sodium hydroxide. For zinc sulphide, however, the measured $\zeta$-potential was seen to vary significantly from 0 to $-50 \mathrm{mV}$ over the $\mathrm{pH}$ range 2-12. To ensure a clear filtrate in all tests and promote cake filtration a microporous, hydrophilic membrane, Versapor manufactured by Gelman Sciences ${ }^{\mathrm{TM}}$ was used as the filter medium. This $0.2 \mu \mathrm{m}$ rated membrane had a nominal thickness of $185 \mu \mathrm{m}$ and a measured hydraulic permeability of $7.0 \times 10^{-15} \mathrm{~m}^{2}$.

\section{EXPERIMENTAL RESULTS}

Sequences of tests were performed to investigate the influence of both particulate and process variables on the constant pressure filtration of aqueous calcite and zinc sulphide suspensions (see Table 2). The sample data shown in Figures 4-15 highlight the effects of initial suspension concentration, applied filtration pressure, suspension $\mathrm{pH}$ and filtration area. To examine the individual influence of each variable on filtration, all parameters, other than the one being examined, were maintained as constant as experimentally possible during a sequence of tests. Many more data were acquired in confirmation of the results shown.

\section{General Data Trends and Data Analysis}

\footnotetext{
${ }^{\dagger}$ It is noted that the compressibility of the zinc sulphide system was significantly affected by suspension $\mathrm{pH}$ and the system could behave in an incompressible manner when conditions allowed.
} 
Whilst the parameters shown in Table 2 affected the dead-end filtration of the suspensions to an extent dependent on their relative magnitudes the majority of experimental data showed the same general trends. When filtration was initiated the (clear) filtrate flow would progressively decrease from its initial value as cake thickness increased. Standard plots of time/volume vs. cumulative volume (i.e. $t / V$ vs. $V$ ) generally showed as straight lines in accordance with conventional theory and the measured solids concentration profile within a growing cake was dependent on the suspension being filtered. Figure 4 shows typical solids concentration profiles through the whole height of cake/suspension for both $10 \% \mathrm{v} / \mathrm{v}$ calcite and zinc sulphide suspensions filtered at 600 $\mathrm{kPa}$. The calcite data are representative of incompressible cake formation where the electrode readings indicate similar values of concentration throughout the cake height. For more compressible zinc sulphide cakes filtration times were generally longer and a wider spread of concentration values through the cake were typically seen. Such data indicate the ability to readily distinguish between incompressible and compressible filter cakes and to give values of solids concentration throughout a filtering suspension/cake. Sequences of tests performed at all scales showed similar general trends.

For the purpose of this paper conventional filtration theory has been employed to analyse the experimental data. The method was chosen because it is used by the majority of industry in calculations and delivers the characterising parameters frequently used in scale-up procedures. However, care was taken to ensure consistent data analysis. To facilitate analysis average cake solids concentrations were calculated for each of the tests performed. A procedure was adopted whereby the position of the cake/suspension interface was identified through a fixed solids concentration and the area under height vs. solids concentration plots determined by numerical integration after a given volume of filtrate had been produced in a test. To obtain average specific cake resistance the gradient of a $t / V$ vs. $V$ graph was determined by linear regression and the previously calculated average cake concentration was then used in eqn. (1) to give the required resistance value. In order to calculate the pressure gradient across the cake alone it was first necessary to determine the pressure loss across the filter medium. This was done from the intercept $\left(c_{i}\right)$ of the $t / V$ vs. $V$ graph such that

$$
R_{m}=\frac{c_{i} A \Delta P}{\mu}
$$

whence the pressure gradients across the medium $\left(\Delta P_{m}\right)$ and the cake $\left(\Delta P_{c}\right)$ could be calculated by Darcy's Law

$$
\begin{aligned}
& \Delta P=\mu R_{m} \frac{Q}{A} \\
& \Delta P_{c}=\Delta P-\Delta P_{m}
\end{aligned}
$$

where $Q$ is filtrate flow rate. Hence, by following the consistent analysis procedure and using eqns. (2)-(6) it was possible to determine the four scale-up constants required to characterise filtrations ${ }^{40}$. It is noted in passing that the majority of the tests with zinc sulphide gave negative intercepts on $t / V$ vs. $V$ plots and filter medium resistances (a well known phenomena in compressible cake filtration ${ }^{41}$ ). When a negative intercept was encountered the resistance of the unfiltered membrane was used in calculations ${ }^{\dagger}$. In general terms the measured cake resistances for calcite were significantly lower than those for zinc sulphide with maximum cake concentrations in both cases ranging between $40 \& 50 \% \mathrm{v} / \mathrm{v}$. Samples of the cakes were taken at the end of all filtration experiments to verify the solids concentrations determined from the electrode pairs.

\footnotetext{
${ }^{\dagger}$ It is recognised that the initial gradient of the volume-time data could be used to obtain the resistance of the filter medium. The authors do not believe that the accuracy of this technique is high when taking gradients over the relatively narrow range of data available.
} 


\section{Effects of Filtration Pressure}

Figure 5 shows typical $t / V$ vs. $V$ relationships for a sequence of filtration tests with calcite at six different applied pressures. By increasing the pressure the gradient of the data was observed to decrease sequentially in the expected manner. The decrease in gradient became progressively smaller as the pressure was raised, indicating the reducing advantage of operating at ever higher pressures. The situation became more extreme when apparently very incompressible systems, such as zinc sulphide suspensions at $\mathrm{pH}=10.5$, showed an overlay of $t / V \mathrm{vs}$. $V$ data at pressures in the range $400-600 \mathrm{kPa}$. The calculated resistance of the filter medium was generally seen to increase with applied pressure. As no significant internal fouling of the membranes was measurable in post-filtration porometer tests it was concluded that some medium compression was taking place at the higher pressures. Figure 6 shows that changes in solids concentration profiles could be observed during filtrations at different constant pressures. After a given filtration time the more compressible zinc sulphide system showed both increased cake height and a progressive increase in filter cake concentration with applied pressure. With calcite a raised pressure led to a faster cake formation rate but no significant change in cake concentration.

From the sequences of tests at applied pressures between $50 \& 600 \mathrm{kPa}$ it was possible to calculate average cake solids concentrations and specific cake resistances using the procedures outlined earlier. Thus, the four scale-up constants required to characterise a filtering system could be evaluated and typical values are shown in Table 3.

\section{Effects of Initial Suspension Concentration}

For both the calcite and zinc sulphide systems faster filtration rates were generally seen with lower feed concentrations; these faster rates being accompanied by different cake growth rates. Figure 7 shows data at three different feed concentrations were a $20 \% \mathrm{v} / \mathrm{v}$ suspension formed a thicker cake than a $5 \% \mathrm{v} / \mathrm{v}$ suspension in a given time. With calcite the measured cake concentrations remained essentially constant for different initial suspension concentrations, whereas some experiments with zinc sulphide gave lower cake resistance values with increased feed concentration. This was thought to be due to different bridging interactions at the cake/membrane interfaces.

\section{Effects of Time}

As time proceeded through a filtration changes generally occurred in the measured cake concentration profiles. For calcite the cake height was seen to increase with time, but the cake concentrations remained at essentially the same value throughout a filtration. For the more compressible zinc sulphide system cake height would again increase with time but in this case the measured cake concentrations also progressively increased to give higher concentrations later in the tests. The degree to which the concentrations increased was influenced by the addition of ionic species to the feed, the pressure applied throughout filtration and the inherent compressibility of the cake.

Figures $8 \& 9$ show that some curious results could be obtained with zinc sulphide filtrations after longer time periods. Figure 8 gives the $t / V$ vs. $V$ relationship for a zinc sulphide suspension filtered at $100 \mathrm{kPa}$. In this particular experiment a large deviation from the expected straight line behaviour was seen after approximately $9000 \mathrm{~s}$ filtration. The filtrate flow rate seen at point $\underline{B}$ increased to three times the rate experienced at point $\underline{A}$ and then reduced again to a value close to the original filtrate flow rate at point $\underline{\mathrm{C}}$. Corresponding solids concentration profiles from the electrode pairs at 10,15 and $20 \mathrm{~mm}$ above the filtering membrane are given in Figure 9 . It is seen that between points $\underline{B}$ and $\underline{C}$ the measured solids concentrations either remained essentially constant or reduced and then increased more sharply at the point $\underline{\mathrm{C}}$. The time over which the filtration took place was significant and it is possible that the relatively unstable suspension @ $\mathrm{pH}=$ 
2.5 had formed a filter cake by a combination of filtration and sedimentation with a quantity of supernatant thus being present above the cake. This supernatant may have subsequently permeated through the formed cake. It is interesting to note, however, the high filtration rates between the points $\underline{B}$ and $\underline{C}$ and that the gradient of the $t / V$ vs. $V$ plot after point $\underline{C}$ appears to be very similar to that recorded up to the point $\underline{A}$ indicating that suspension was still present above the cake. The filtrate remained clear throughout the test and similar behaviour was seen in several other tests with zinc sulphide.

\section{Effects of Particle Surface Charge (Suspension pH)}

Whilst changing $\mathrm{pH}$, and hence particle surface charge, had a negligible effect on the filtration performance of calcite suspensions, Figure 10 shows filtration data for $10 \% \mathrm{v} / \mathrm{v}$ zinc sulphide suspensions at three different $\mathrm{pH}$ 's. Here the rate of filtration was highest @ $\mathrm{pH}=6.0$ and lowest $@ \mathrm{pH}=10.5$, with a suspension @ pH=2.5 giving a rate between the two. Figure 11 shows the concentration profiles for the same three experiments after $8000 \mathrm{~s}$ filtration. The data clearly indicate the suspension @ pH=6.0 to give the lowest solids concentration adjacent to the septum with the suspension @ pH =10.5 giving the highest and the suspension @ pH=2.5 again showing between the two.

By changing the $\mathrm{pH}$ of a zinc sulphide suspension, and hence the ionic strength of the solution environment, both the filtration and sedimentation behaviour were altered. Suspensions @ pH= 10.5 were very stable and did not settle to any appreciable extent, whereas suspensions @ $\mathrm{pH}=$ 6.0 and $\mathrm{pH}=2.5$ settled more rapidly. Table 1 shows that at higher $\mathrm{pH}$ values particles in a suspension were kept more discrete by the electrostatic repulsion forces present. It seemed that when filtering these particulates would pack more closely to give higher cake concentrations and subsequently lower filtration rates. When suspension $\mathrm{pH}$ was lowered nearer to 6.0 , the repulsion forces decreased according to Figure 3 and the attractive van der Waals forces induced more particle aggregation. Filtration became easier through these more loosely packed aggregates as the cake concentration was reduced. At pH values closer to the iso-electric point (IEP) zinc sulphide particles again appeared to pack more closely together under the influence of the attractive forces to form more resistant cakes. The situation with $\mathrm{pH}$ is made more complex by the presence of the Dispex on the particles and the fact that particle size distribution alters with changing particle surface charge. What is notable, however, is the clear correlation between cake concentration adjacent to the filtering surface and the rate of filtration.

\section{Effects of the Scale of Filtration}

Perhaps the most interesting, even controversial, results were obtained when the influence of scale of filtration was examined. Whilst sequences of tests performed using areas between 5 \& $490 \mathrm{~cm}^{2}$ showed similar general trends when process parameters such as pressure and suspension $\mathrm{pH}$ were altered, significant differences were recorded when scale-up constants and specific cake resistances were evaluated using the procedures described.

Table 3 shows values for the scale-up constants evaluated from sequences of $10 \% \mathrm{v} / \mathrm{v}$ calcite and zinc sulphide experiments. The data suggest that the magnitude of the 'constants' may vary with scale to an extent dependent on the properties of the feed and the area of filtration. With calcite there appeared to be no definitive trends in $n, \alpha_{0}, m$ or $C_{0}$ with scale, however, the data do show apparently random variation as scale is varied. In contrast some of the zinc sulphide data showed clearer trends with scale. Although experiments @ $\mathrm{pH}=2.5$ gave little indication of scale effects, experiments @ pH = 6.0 indicated a general decrease in the value of $n$ with increasing filtration area and a progressive increase in $\alpha_{0}$ of more than an order of magnitude over the range of areas tested. Values of $m$ and $C_{0}$ did not appear to exhibit corresponding trends. Too few data were available @ pH = 10.5 to draw meaningful conclusions. 
Although the data obtained at the various scales of filtration were repeatable they can be interpreted in a variety of ways. For instance, Figure 12 demonstrates the apparent influence of scale on values of average specific cake resistance calculated from a total of forty $t / V$ vs. $V$ plots. Data sequences from twenty calcite experiments over the pressure range 100-600 kPa showed little dependence on test pressure but an apparent minimum in measured specific cake resistance for the filter cell having an area of $23 \mathrm{~cm}^{2}$. A corresponding set of twenty data sequences for zinc sulphide experiments failed to show a minimum, however, a generally increasing cake resistance with increasing filter cell area was observed in conjunction with the expected step-wise influence of pressure. Figure 13 shows how some measured solids concentration data also indicated apparent variance with scale. The same filtration experiments can also be interpreted using the derived scale-up constants shown in Table 3. In Figures 14 \& 15 eqns. (2) \& (3) have been used in conjunction with some of the data from Table 3 to calculate values of average specific cake resistance over a range of pressures for calcite suspensions and zinc sulphide suspensions at $\mathrm{pH}$ $=6.0$. The data for calcite in Figure 14 confirm the relevant trends shown in Figure 12 where a significantly lower specific cake resistance is seen for a filter area of $23 \mathrm{~cm}^{2}$. However, the data shown in Figure 15 for zinc sulphide indicate the significant differences between calculated cake resistances at areas of 5,23 and $170 \mathrm{~cm}^{2}$ and those calculated at a filtration area of $490 \mathrm{~cm}^{2}$. Whilst these relatively large differences are less apparent on Figure 12 for zinc sulphide, similar trends are seen on both plots and comparisons of Figures 12 and 15 highlight some of the difficulties involved in analysing and interpreting filtration data even when care is taken in the experimentation and data acquisition. Sufficient filtration data were acquired over ranges of experimental conditions to confirm the trends presented in Figures 12-15 and, in the authors opinion, the data suggest that scale effects are real and of sufficient magnitude to significantly influence filtration performance when conditions allow.

\section{DISCUSSION}

Filtration is a far more complex process than first impressions might suggest. A host of parameters affect the manner in which a cake is formed and researchers have struggled for many years to quantify their influence. In the following the effects of some of these parameters are highlighted with particular reference to filtration time and the scale of filtration.

The data presented in this paper simultaneously support and contradict several findings from the existing research literature. Perhaps the best illustration is the previously reported existence of retarded packing compressibility (RPC). This apparent cake collapse was first reported in 1953 by Rietema ${ }^{42}$, subsequently by Baird et al. ${ }^{27}$ in 1967 and (seemingly) more recently by Theliander et al. $^{43}$ and Sorenson et al. ${ }^{44}$. The initial cake structure, supposedly stabilised by high initial flow rates $^{42}$, collapses when the filtrate flow rate decreases at a later time in a filtration. The porosity of the cake is thought to decrease as cake resistance increases leading eventually to lower filtration rates. Wakeman ${ }^{45}$ deduced that cake collapse invalidates the assumption of point contact between particles in a cake as the force-momentum balances are not complete. Banda et al. ${ }^{46}$ provided experimental evidence that particles are not always in point contact by examining micrographs of particulate filter cakes. Shirato et al. ${ }^{23,24}$ disagree with the concept of RPC and point to the use of intrusive electrodes in filter cells providing support to the cake and not allowing normal compression to occur (it is noted in passing that Theliander used pressure probes). The situation is perhaps made more confusing by the work of Heertjes ${ }^{5,18}$ and Sorenson et al. ${ }^{46}$. In the former cake solids concentration is reported a maximum not at the cake/medium interface but rather at a position further into the cake away from the medium. Sorenson et al. have reported temporary increases in filtrate flow part way through filtration tests with this increase being accompanied by a sudden increase in the turbidity of the filtrate. After a period of time the filtration rate returned once more to the original level. The data presented in Figures 8 and 9 show simultaneous measurements of changes in cake concentration and corresponding changes in filtrate flow. By providing carefully controlled and instrumented apparatus such measurements 
become routine, however, they do not provide the whole picture, merely a basis from which to progress knowledge.

It is possible to postulate the causes of RPC as it is quite reasonable to suggest that all previously reported instances are either different facets of the same phenomenon or simply erroneous experiments. Previous researchers ${ }^{46}$ have suggested that smaller sized particles in the cake migrate locally to either increase the flow resistance or promote the formation of channels. In the former case cake resistance would be seen to increase provided the filtrate remained clear whereas for channels to form a cake would need to locally 'expand' or collapse away from a region (under the applied compressive pressures !) to allow a clearer passage for the filtrate. The data shown in Figures 8 \& 9 suggest that the sudden increases in filtrate flow are accompanied in some manner by a reduction in measured cake concentration. Both of these observations could be explained by particle migration and channel formation, however, if RPC does exist then our current level of knowledge is insufficient to determine why.

The relative dearth of literature relating the effects of scale in filtration maybe epitomises the challenges faced by separations technologists. They are continually required to predict larger scale filtration performance from relatively small scale test data merely with the use of pastexperience and empirically derived rules ${ }^{47}$. The generally accepted practice is to perform a series of leaf filtration tests to give an estimate of the required filtration area through eqn. (1). An empirically derived factor of $25 \%$ is then applied to filter area to 'correctly' size the filter. Whilst this procedure may give adequate answers in some cases, it is seemingly based on heuristics rather than fundamental science. The experimental data shown in Figures 12-15 and Table 3 perhaps, for the first time, give some quantitative measure of scale effects in pressure leaf filtration. There is sufficient evidence to suggest that the scale-up constants vary in magnitude both with scale and process conditions. Moreover, several experimental data sequences, interpreted through the general filtration equation, show general trends in the characterising parameters of specific cake resistance and cake concentration when equations (2) and (3) are utilised.

To fully appreciate the consequences of scale, and eliminate the need for interpretative filtration models, it is necessary to provide an indication of overall filter performance. Cumulative volumetime data from calcite and zinc sulphide filtrations at four different scales and otherwise identical process conditions showed the expected progressions where an increased filtration area produced a greater volume of filtrate in a given time. When the same data, however, were amended to give corresponding cumulative volume of filtrate per unit area-time plots the data shown in Figures 16 \& 17 were produced. With no influence of scale it would be reasonable to expect the volume of filtrate per unit area to be the same for each sequence of tests. Figure 16 shows that for calcite tests and filtration areas of 5,170 and $490 \mathrm{~cm}^{2}$, only a small influence of scale was manifested; Figures $12 \& 13$ highlight the measured specific cake resistances and cake concentrations in these cases. The situation was not the same when a filter area of $23 \mathrm{~cm}^{2}$ was employed as a significantly larger amount of filtrate was produced per unit area throughout the filtration. In this case Figures 12 \& 13 show a lower measured specific cake resistance and marginally higher cake concentration respectively. At first it may be tempting to dismiss the minimum observed in Figure 12 as a 'freak' result, however many other similar data were obtained for calcite to confirm the observed minimum and the result must be considered valid. The data shown in Figure 17 for zinc sulphide filtrations further emphasise the apparent effects of scale. Here, a descending progression in the values of volume per unit area was observed as the scale of filtration varied between $5 \& 490 \mathrm{~cm}^{2}$. The data in Figures $12 \& 13$ show the variability of both specific cake resistance and measured cake concentrations with scale as does the corresponding data in Table $3^{\dagger}$. The significance of these scale results should not be underestimated as the data in Figures $16 \& 17$ were produced without an interpretative model.

${ }^{\dagger}$ The data values shown in Figures $14 \& 15$ were calculated from the scale-up constants derived for the experiments illustrated in Figure 12. Although Figures 14 \& 15 may suggest a slightly different interpretation of the experimental results the general data trends are similar to Figure 12 
Postulations for the observed effects of scale may range from wall effects through to variations in the structuring of suspensions/cakes and changing hydrodynamic flow patterns in the different filters. Wall effects have previously been reported to influence filtration in C-P cells ${ }^{33-35,48}$ and with the diameter of the filter cells ranging between $25 \& 250 \mathrm{~mm}$ it is reasonable to assume that they may be having an influence in the current work. Tiller ${ }^{34}$ has reported C-P data for solka-floc suspensions were the aspect ratio (i.e. height/diameter) of the formed cake was varied over the range 0.1-1.2. As the aspect ratio was increased so more of the mechanical pressure applied to the cake was effectively dissipated by the cell walls, thereby reducing the transmitted pressure and filtration rate. Thus, if these results can be transposed to leaf filters then the filter cell with the smallest area would be expected to produce lower volumes of filtrate per unit area. That the converse appears to be the case is interesting and perhaps suggests that the observed behaviour is due to other underlying reasons. The data in Figures $12 \& 13$ for zinc sulphide suggest that the cake concentration decreases as specific cake resistance increases. This apparently contradictory evidence suggests two possible reasons for the behaviour shown in Figure 17. The lowering of cake concentration with scale is indicative of a reducing available driving pressure for filtration and would explain the results shown in Figure 17 on the basis of reduced cake compression. An increasing specific cake resistance with scale would also account for the effects shown due to the raised resistance to filtrate flow. Reconciling the simultaneous influences of cake concentration and specific resistance is more difficult as is the data for calcite with a filtration area of $23 \mathrm{~cm}^{2}$.

If the suspensions are showing some evidence of structure, as the zinc sulphide with added Dispex may be, then relatively long-range interactions may be affecting the filtration in a manner which is impossible to quantify from the current work. The potential for different hydrodynamic flow patterns within the filters is just as difficult to interpret. Whilst care was taken to maintain constant conditions between corresponding experiments at different scales some unavoidable variations in flows may have occurred. For different flow patterns to influence filtration and account for the sometimes significant scale effects observed in the experiments then particle properties and cake formation would need to significantly altered by the changing flows. Although it is difficult to envisage how such major alterations to suspension properties could have occurred with the near identical filter configurations employed the influences of flow variation are difficult to dismiss completely. It is widely accepted that the acquisition of reliable filtration data becomes more difficult as the scale of operation is increased. Without further experimentation though, ideally at larger scales using a wider range of suspensions, the underlying reasons for the apparent effects of scale observed by the authors will remain hypothetical. What is clear, however, is support for the method of experiment analysis as there are trend correlations between the data shown in Figures 12-15 and those data shown in Figures $16 \& 17$.

The authors are unaware of previous work which shows the effects of scale in filtration in quite such an explicit form. Although the reasons for the influence of scale are currently unclear, the effects appear to be real and suggest a number of recommendations. It is apparent from an industrial viewpoint that performing tests at an inappropriate scale in the laboratory can lead to an incorrectly sized filter. The importance of performing tests at the largest possible scale is obvious, but until a deeper fundamental insight is gained into the effects of scale the use of scaling or safety factors is likely to remain a necessity with the level of correction being the contentious issue. If the data presented in this paper are confirmed by further experimentation at still larger scales then strong evidence will exist to suggest that the current practice of using a $25 \%$ correction for filter area is insufficient in many cases. However, it is presently difficult to provide definitive values for the necessary correction factors. It is suspected that the effects of scale seen in the current work will reduce as the scale of operation increases. The four characterising scale-up parameters for cake filtration are also thought to be inadequate. Whilst $n$ and $\alpha_{0}$ provide reasonable, though inexorably linked, measures of compressibility and cake resistance the experimental data suggest

and consistent with the data shown in Figures $16 \& 17$ which were produced without an interpretive model. 
that for even small changes in cake structure, and hence $C_{0}$ and $m$, relatively large changes in cake resistance can be recorded. It would appear that macroscopic cake concentration determinations provide insufficient detail to be useful. Moreover, the work presented in this paper indicates the ever growing need to provide standard, well controlled equipment for monitoring filtration performance and reliable methodologies and models for predicting filter performance. By doing so researchers and industrialists can establish a firm, coherently documented, base from which to progress filtration research in the future.

\section{CONCLUSIONS}

The filtration literature to the non-expert is often viewed as a confusing collection of individual facts which are difficult to piece together. Few, if any, detailed systematic investigations of filtration have been performed in the past due to either a lack of suitable equipment or the pressures of time and it is possible that many of the results found in the literature form only parts of a coherent overall picture. By providing consistent analysis procedures and a well controlled and fully instrumented experimental apparatus it has been possible to show the effects of several process parameters. It is believed that the results concerning scale are rare and demonstrate in microcosm the difficulties that separation experts face in progressing our filtration knowledge base. There is a clear need to move away from the heuristics currently used in filter design and scale-up towards well-defined and sound methodologies. The ability to do this would undoubtedly help the filter designer in the economic specification of large scale apparatus and, indeed, with the efficient operation of such devices.

\section{ACKNOWLEDGEMENT}

The authors gratefully acknowledge the financial support of the EPSRC for this work.

\section{NOMENCLATURE}

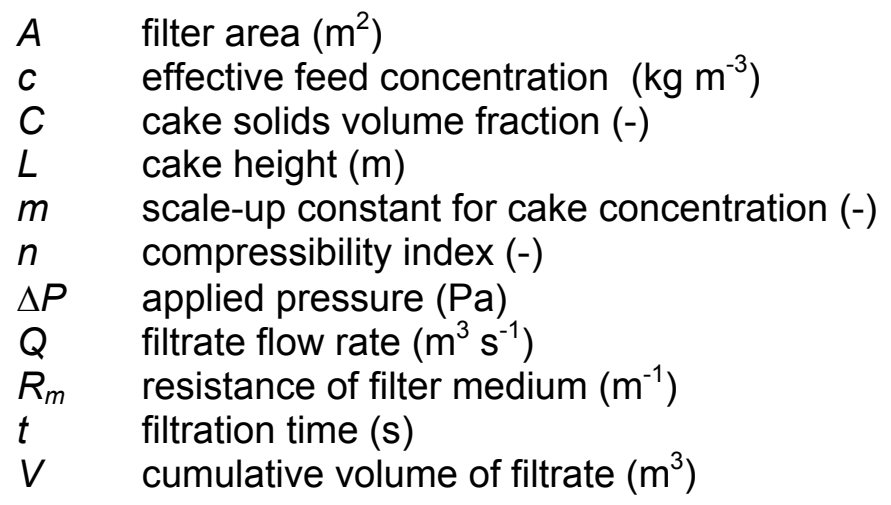

\section{Greek symbols}

$$
\begin{array}{ll}
\alpha & \text { specific cake resistance }\left(\mathrm{m} \mathrm{kg}^{-1}\right) \\
\mu & \text { dynamic viscosity of filtrate }(\mathrm{Pa} \mathrm{s}) \\
\sigma & \text { standard deviation }\left(\mathrm{m} \mathrm{kg}^{-1} \text { or }-\right)
\end{array}
$$

\section{Subscripts and other symbols}

c value at the cake

$m \quad$ value at the medium

0 at unit applied pressure 


\section{REFERENCES}

1. Sperry D.R., 1916, The principles of filtration I, Met. Chem. Eng., 15: 203.

2. Ruth B.F., 1946, Correlating filtration theory with industrial practice, Ind. \& Eng. Chem., 38: 564.

3. Grace H.P., 1953, Resistance and compressibility of filter cakes (Part 1), CEP, 49(6): 303.

4. Tiller F.M., 1975, Solid-Liquid Separation (2 ${ }^{\text {nd }}$ Edn.), University of Houston.

5. Heertjes P.M., 1959, The influence of the initial filtration velocity and vibration on the resistance of a polystyrene filter cake, Chem. Eng. Sci., 10: 139.

6. Hameed M.S., 1970, General studies on the rotary vacuum filter, Ph.D. Thesis, University of Manchester.

7. Tiller F.M., 1953, The role of porosity in filtration I, CEP, 49: 467.

8. Rushton A., Hosseini M. and Hassan I., 1980, The effects of velocity and concentration on filter cake resistance, J. Sep. Proc. Technol., 1: 35.

9. Wakeman R.J., 1979, On the use of compressibility coefficients to model cake filtration process, Proc. $2^{\text {nd }}$ World Filtration Congress, pp.57-65, Filtration Society, London.

10. Grace H.P., 1953, Resistance and compressibility of filter cakes (Part 2), CEP, 49(7): 367.

11. Wakeman R.J., Sabri M.N. and Tarleton E.S., 1991, Factors affecting the formation and properties of wet compacts, Pow. Technol., 65: 283.

12. Rushton A. and Rushton A., 1973, Sedimentation effects in filtration, Filt. and Sep., 10(3): 267.

13. Risbud H.M., 1981, Cake filtration empirically incorporating particle migration, Filt. and Sep., 18(1): 20.

14. McDonogh R.M., Welsch K., Fane A.G. and Fell C.J.D., 1992, Incorporation of the cake pressure profiles in the calculation of the effect of particle charge on the permeability of filter cakes obtained in the filtration of colloids and particulates, J. Mem. Sci., 72: 197.

15. Hlavacek M. and Remy J.F., 1995, Simple relationships among zeta potential, particle size distribution and cake specific resistance for colloid suspensions coagulated with ferric chloride, Sep. Sci. Technol., 30(4): 549.

16. Sharma M. and Zongming L., 1991, A model for clay filter cake properties, Colloids and Surf., 56: 357.

17. Wakeman R.J., Thuraisingham S.T. and Tarleton E.S., 1989, Colloid science in solid-liquid separation technology. Is it important?, Filt. and Sep., 26(4): 277.

18. Heertjes P.M., 1957, Studies in filtration, the initial stages of the cake filtration, Chem. Eng. Sci., 6: 269. 
19. Heertjes P.M., 1964, Filtration, Trans. IChemE, 42: 266.

20. Tiller F.M. and Cooper H.R., 1960, The role of porosity in filtration IV: Constant pressure filtration, AlChEJ, 6: 595.

21. Tarleton E.S. and Wakeman R.J., 1994, Simulation, modelling and sizing of pressure filters, Filt. and Sep., 31(4): 393.

22. Tiller F.M. and Shirato M., 1964, The role of porosity in filtration VI: New definition of filtration resistance, $A / C h E J, 10(1): 61$.

23. Shirato M., Aragaki T., Ichimura K. and Ootsuti N., 1971, Porosity variation in filter cakes under constant pressure filtration, J. Chem. Eng. Japan, 4: 172.

24. Shirato M., and Aragaki T., 1972, Verification of internal flow mechanism theory of cake filtration, Filt. and Sep., 9(3): 290.

25. Wakeman R.J., 1981, The formation and properties of apparently incompressible filter cakes under vacuum on downward facing surfaces, Trans. IChemE, 59: 260.

26. Holdich R.G. and Sinclair I., 1992, Measurement of slurry solids content by electrical conductivity, Pow. Technol., 72: 77.

27. Baird R.L. and Perry M.G., 1967, The distribution of porosity in filter cakes, Filt. and Sep., 4: 471.

28. Bierck J. and Wells S.A., 1988, Compressible cake filtration: Monitoring cake formation and shrinkage using synchrotron X-rays, J. Wat. Pollut. Control Fed., 60(5): 645.

29. Inazumi T. and Kasama S., 1989, Analysis of sinter cake structures by computerised tomography, Proc. $5^{\text {th }}$ Int. Symp. Agglom., pp.599-610, IChemE.

30. Okamura S. and Shirato M., 1955, Liquid-pressure distribution within a cake in constant pressure filtration, J. Chem. Eng. Japan, 19(104): 11.

31. Okamura S. and Shirato M., 1956, The filtration and the ageing of sparking-plug slurries, J. Chem. Eng. Japan, 20(98): 678.

32. Shirato M. and Okamura S., 1959, Behaviour of various kaolin slurries in constant pressure filtration, J. Chem. Eng. Japan, 23(11): 226.

33. Shirato M., Aragaki T., Mori R. and Sawamoto K., 1968, Predictions of constant pressure and constant rate filtrations based upon an approximate correction for side-wall friction in C-P cell data, J. Chem. Eng. Japan, 1: 86.

34. Tiller F.M., Haynes S. and Lu W., 1972, The role of porosity in filtration VII: Effect of side-wall friction in C-P cells, AIChEJ, 1: 13.

35. Tiller F.M. and Lu W., 1972, The role of porosity in filtration VIII: Cake non-uniformity in compression-permeability cells, AIChEJ, 1: 569.

36. Rushton A. and Wakeman R.J., 1977, Theory vs. practice in vacuum pressure and centrifugal filtration, J. Pow. \& Bulk Solids Technol., 1: 58.

37. Rushton A., 1969, The effect of concentration in rotary vacuum filtration, Filt. and Sep., 6: 136. 
38. Purchas D.B. and Wakeman R.J., 1986, Solid/Liquid Separation Equipment Scale-up (2 ${ }^{\text {nd }}$ Edn.), pp.411-446, Uplands Press, London.

39. BS5500, 1982, British Standard for Unfired Fusion Welded Pressure Vessels, BSI, London.

40. Willmer S.A., Tarleton E.S. and Holdich R.G., 1995, The influence of particulate and process variables in compressible cake filtration, Proc. Filtech Conference, pp.49-159, Filtration Society, Karlsruhe.

41. Wronski S.K. and Bin A.K., 1976, Anomalous behaviour during the initial stage of constant pressure filtration, Chem. Eng., 12: 143.

42. Rietema K., 1953, Stabilising effects in compressible filter cakes, Chem. Eng. Sci., 2: 88.

43. Theliander H. and Fathi-Najafi M., 1995, Simulation of the build-up of the filter cake, Proc. Filtech Conference, pp.127-137, Filtration Society, Karlsruhe.

44. Sorensen P.B., Christensen J.R. and Bruus J.H., 1995, Effect of small scale solids migration in filter cakes during filtration of waste water solids suspensions, Water Environ. Research, 67(1): 25.

45. Wakeman R.J., 1981, Thickening and filtration: A review and evaluation of recent research, Trans. IChemE, 59: 147.

46. Banda S.M.H. and Forssberg K.S., 1988, Variation of filter cake permeability with mean pore diameter of the cake, Scandinavian J. Mett., 17: 67.

47. Purchas D.B. and Wakeman R.J., 1986, Solid/Liquid Separation Equipment Scale-up (2 ${ }^{\text {nd }}$ Edn.), pp.1-15, Uplands Press, London.

48. Rushton A., 1976, Liquid-solid separation, recent research evaluated, Filt. and Sep., 13(6): 573. 


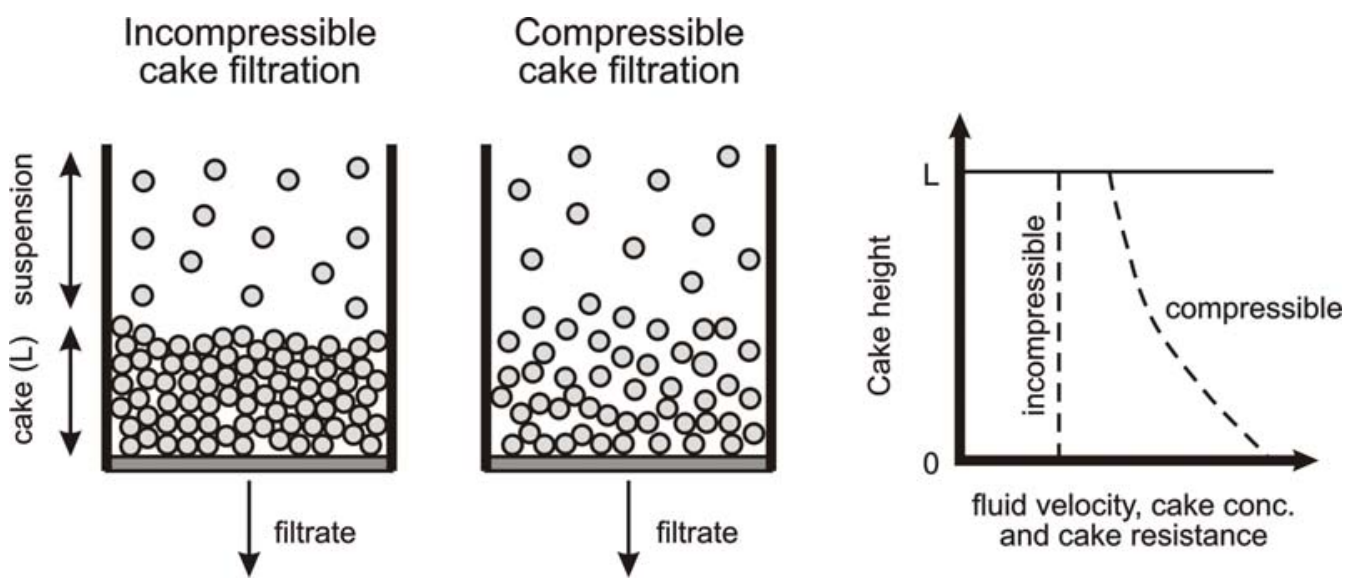

Figure 1: Schematic representation incompressible and compressible cake filtration.

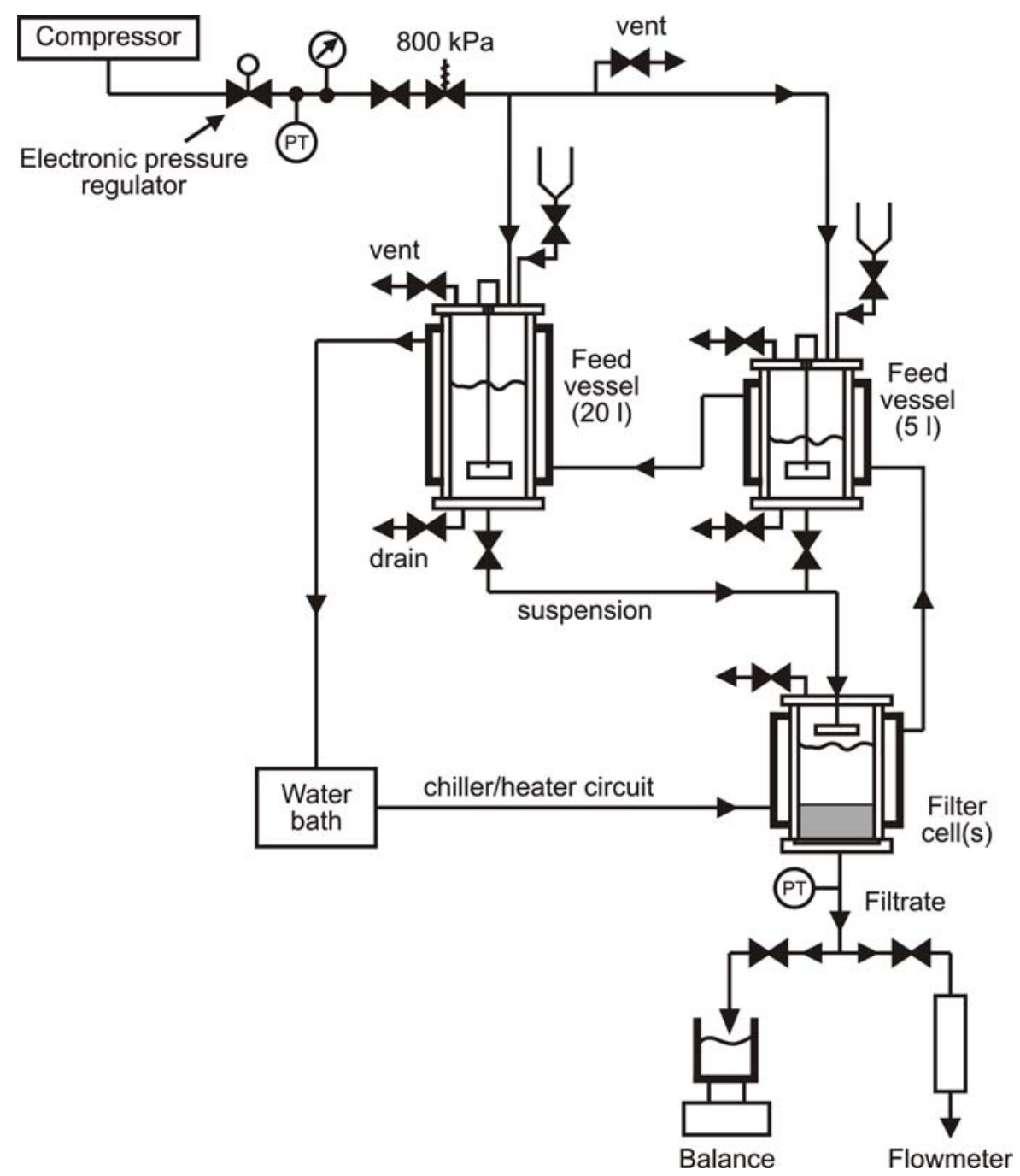

Figure 2: Process flow diagram of the pressure filtration apparatus. 


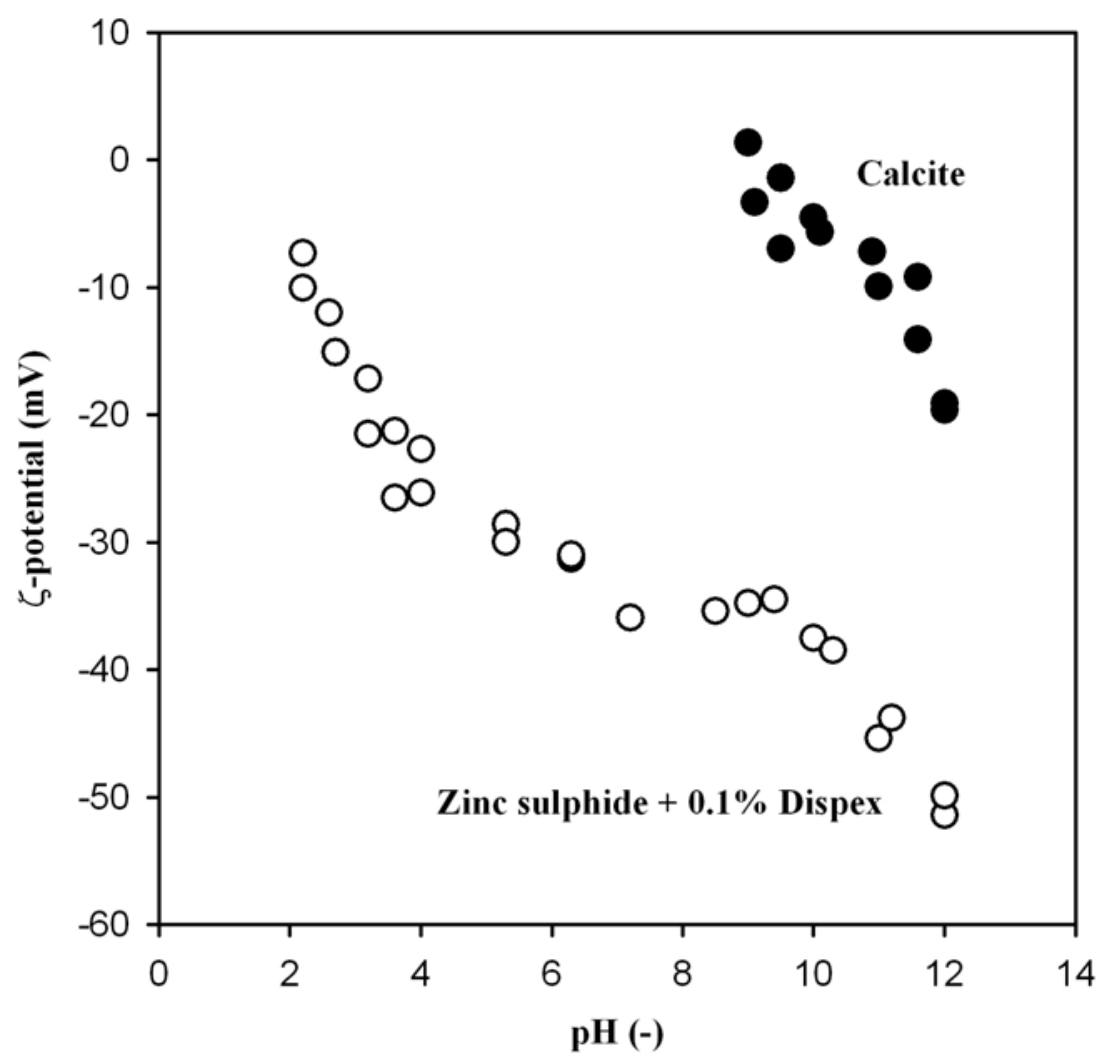

Figure 3: Effect of $\mathrm{pH}$ on $\zeta$-potential for calcite and zinc sulphide powders in distilled water.

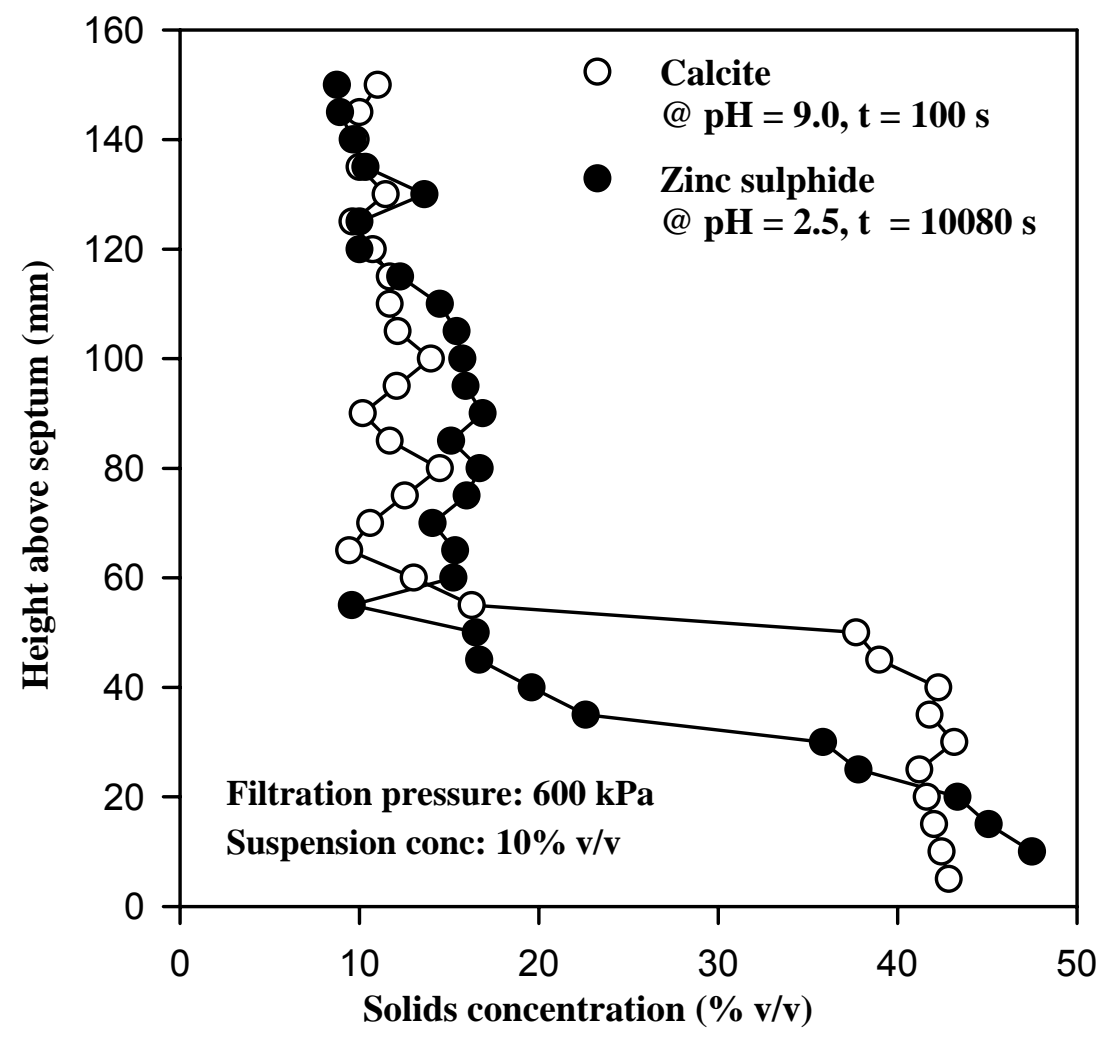

Figure 4: Typical solids concentration profiles for filtering calcite and zinc sulphide suspensions. 


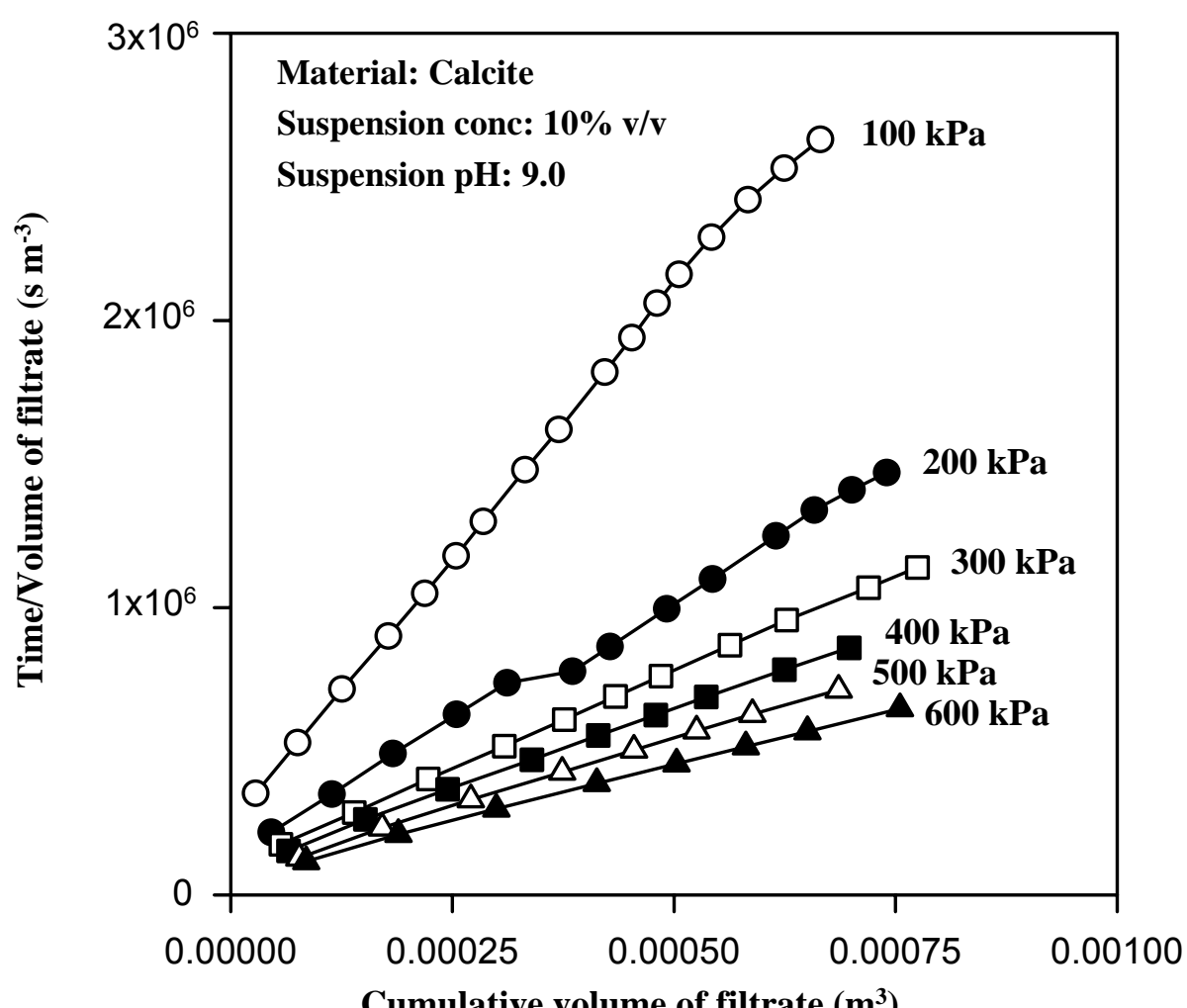

Figure 5: Effect of pressure on the filtration performance of calcite suspensions.

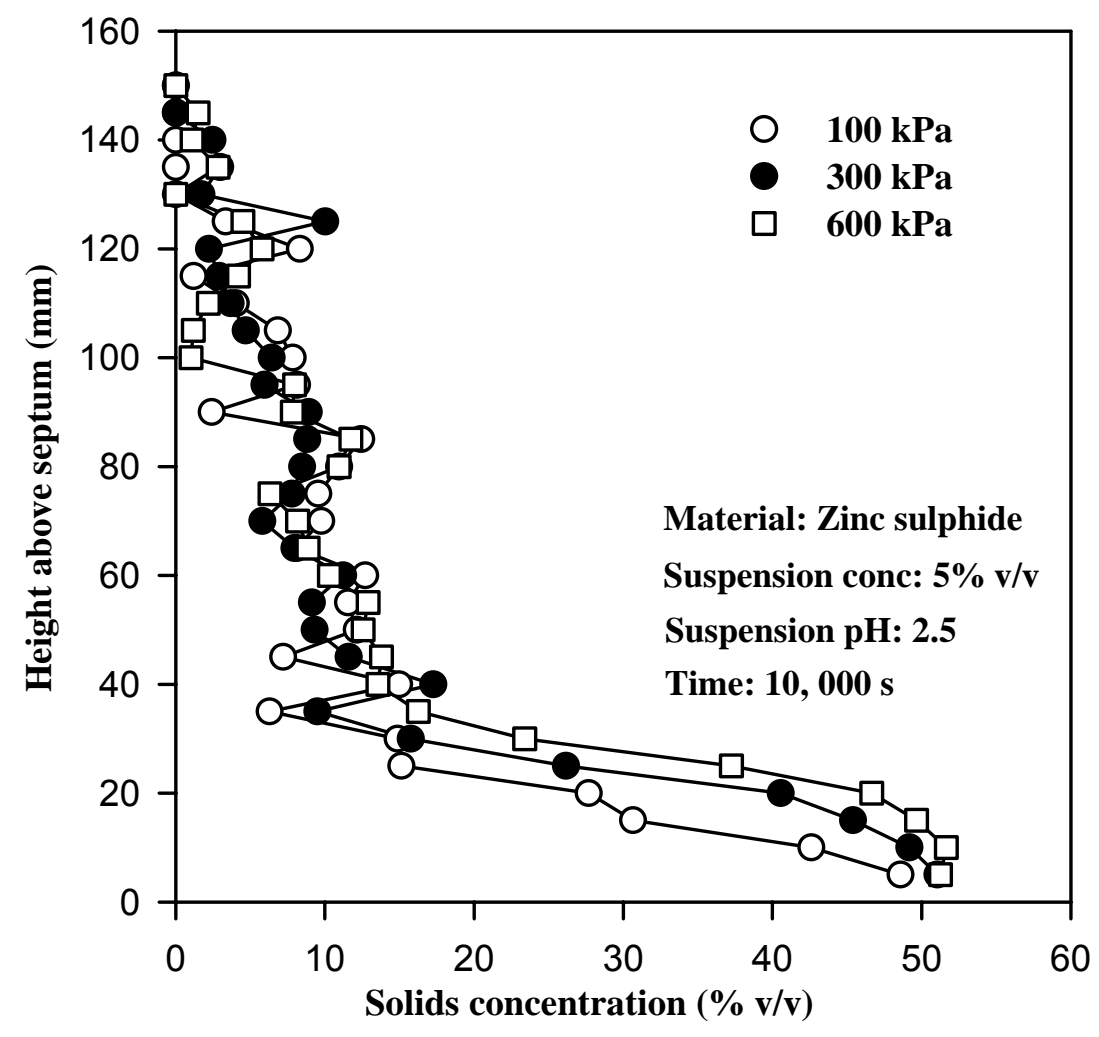

Figure 6: Effect of pressure on solids concentration profiles for zinc sulphide suspensions. 


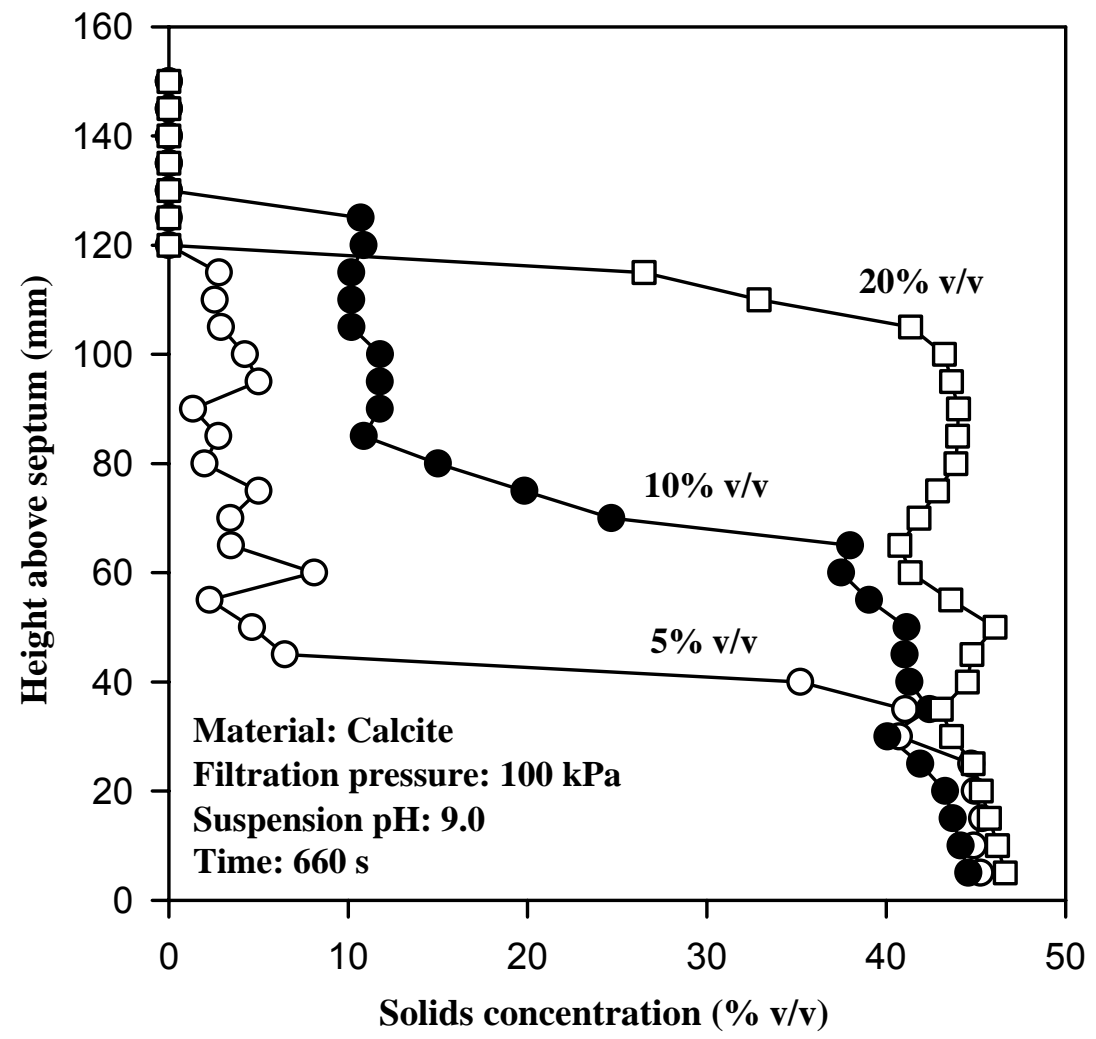

Figure 7: Effect of feed concentration on measured solids concentration profiles for calcite suspensions.

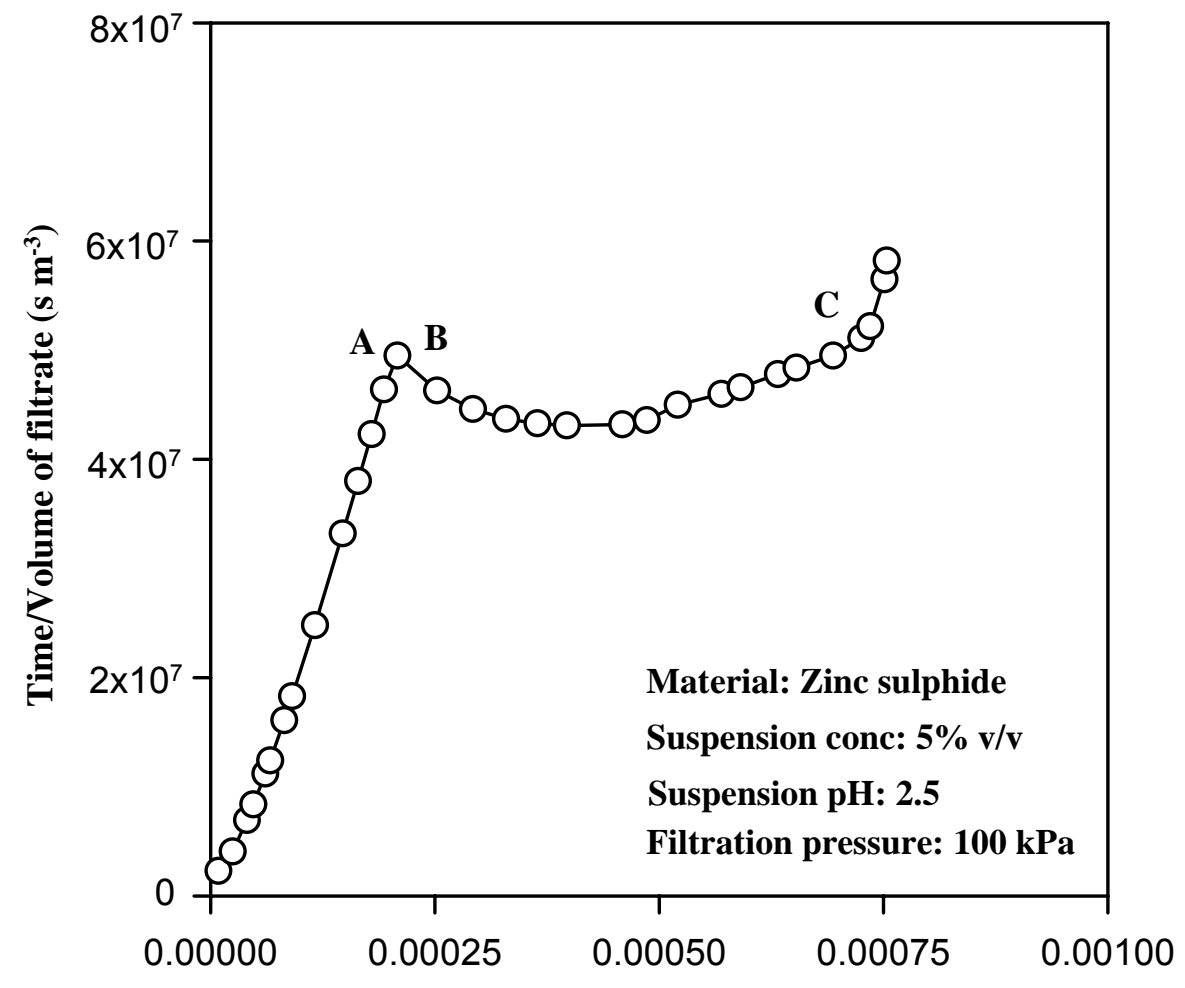

Cumulative volume of filtrate $\left(\mathrm{m}^{3}\right)$

Figure 8: Effect of time on the time/cumulative volume vs. volume relationship for a zinc sulphide suspension. 


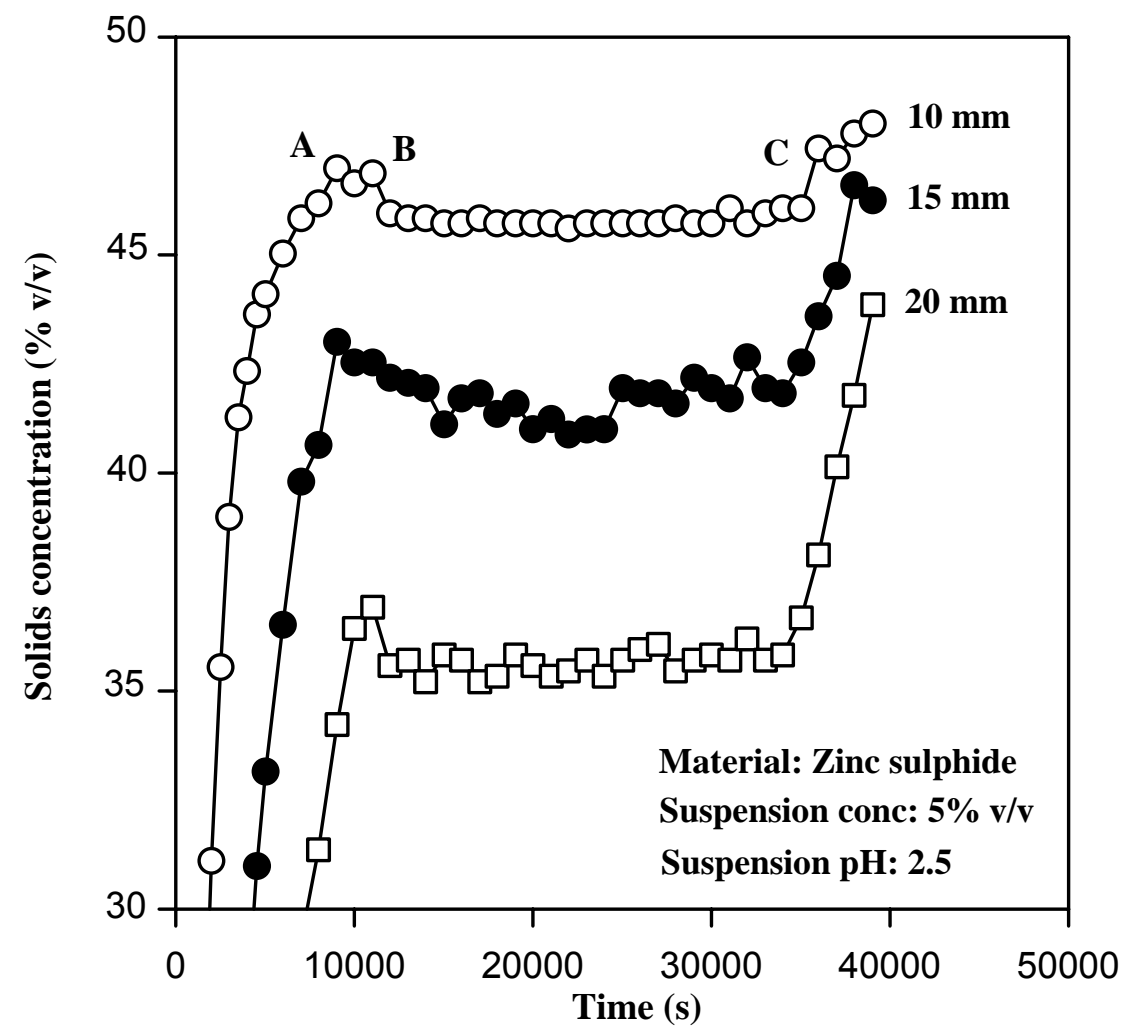

Figure 9: Changes in measured solids concentrations with time for a zinc sulphide suspension.

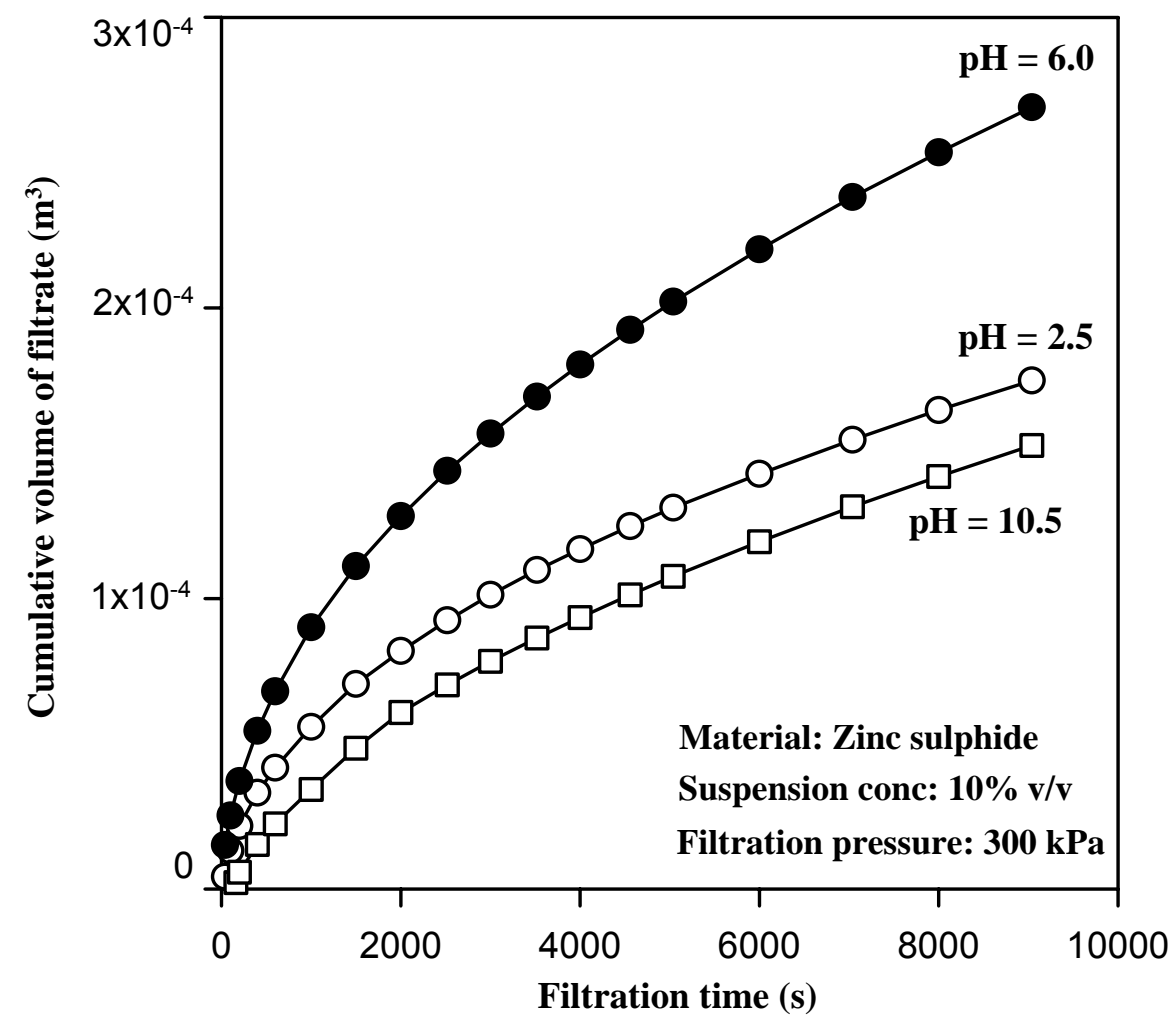

Figure 10: Effect of pH on volume-time relationships for zinc sulphide suspensions. 


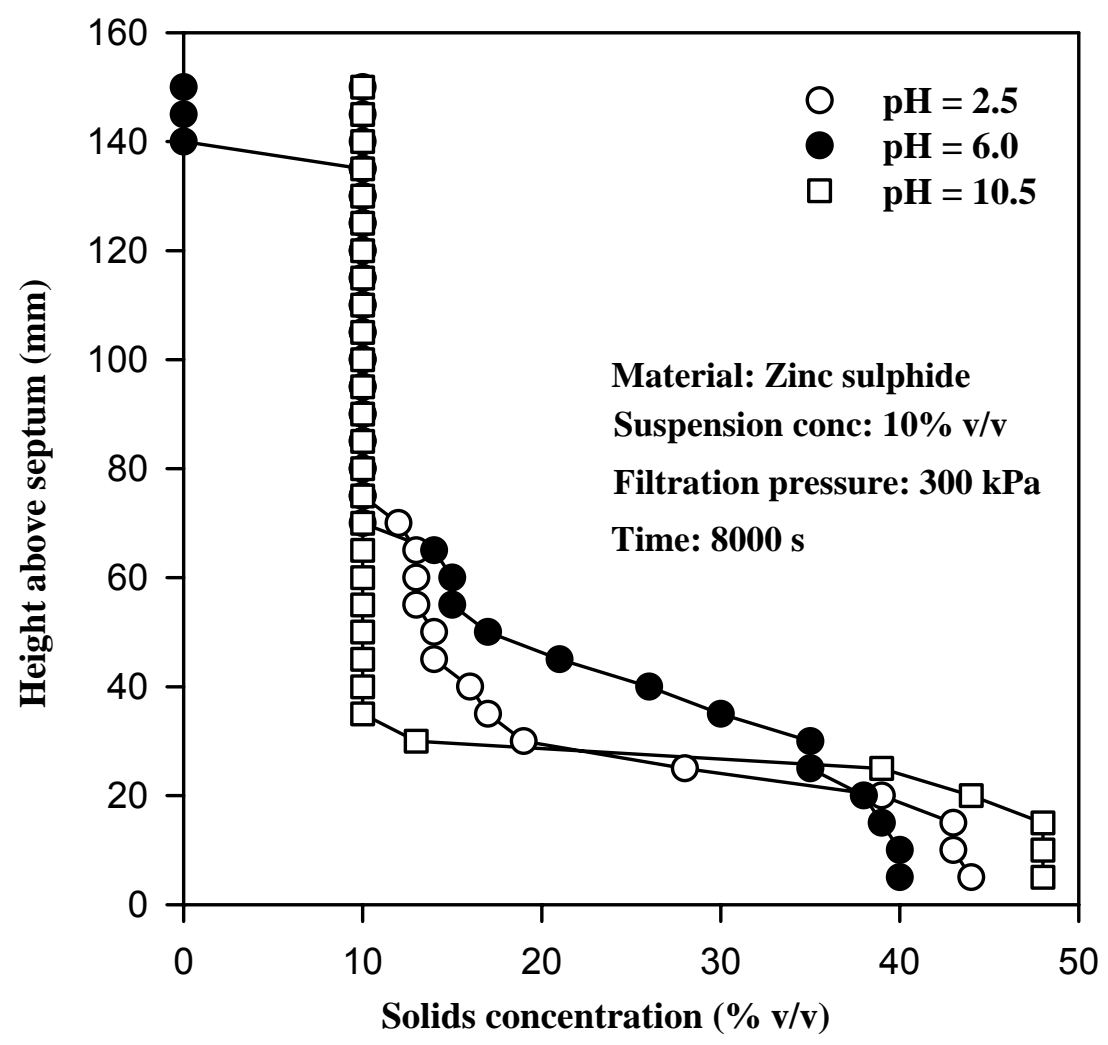

Figure 11: Effect of pH on cake concentration profiles for zinc sulphide suspensions.

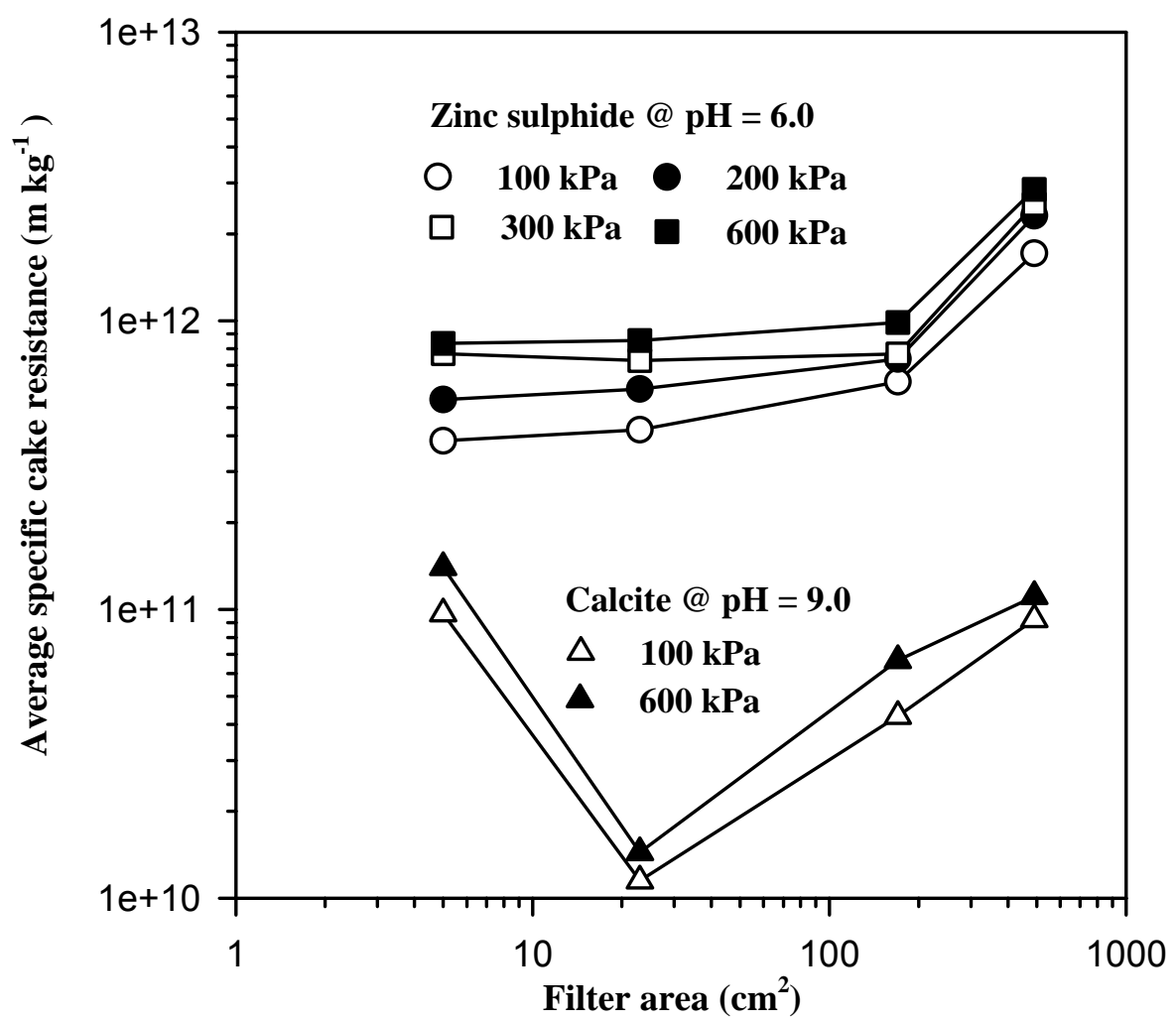

Figure 12: Influence of scale on the measured specific cake resistance of $10 \% \mathrm{v} / \mathrm{v}$ calcite and zinc sulphide suspensions. 


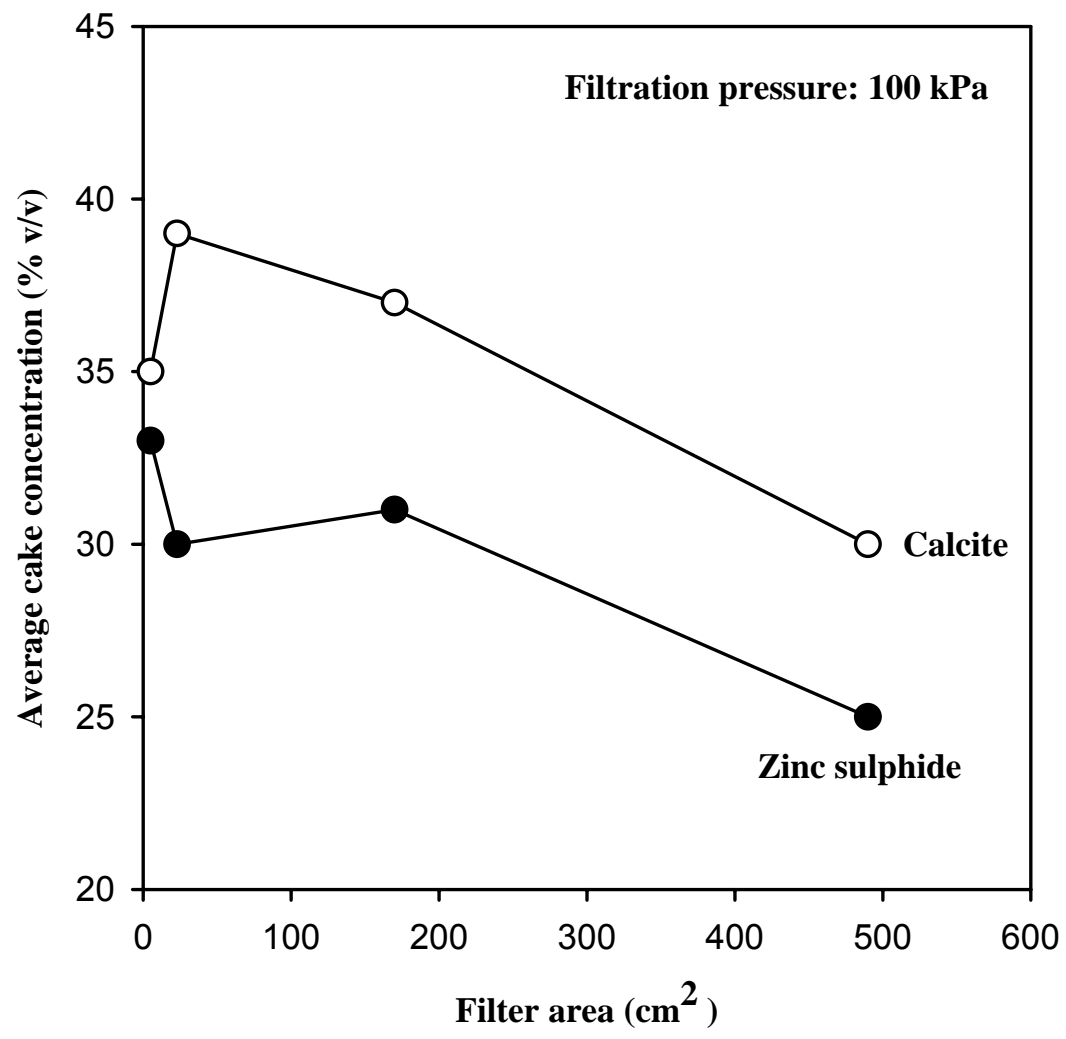

Figure 13: Typical influence of scale on the measured average cake concentrations of $10 \% \mathrm{v} / \mathrm{v}$ calcite and zinc sulphide suspensions.

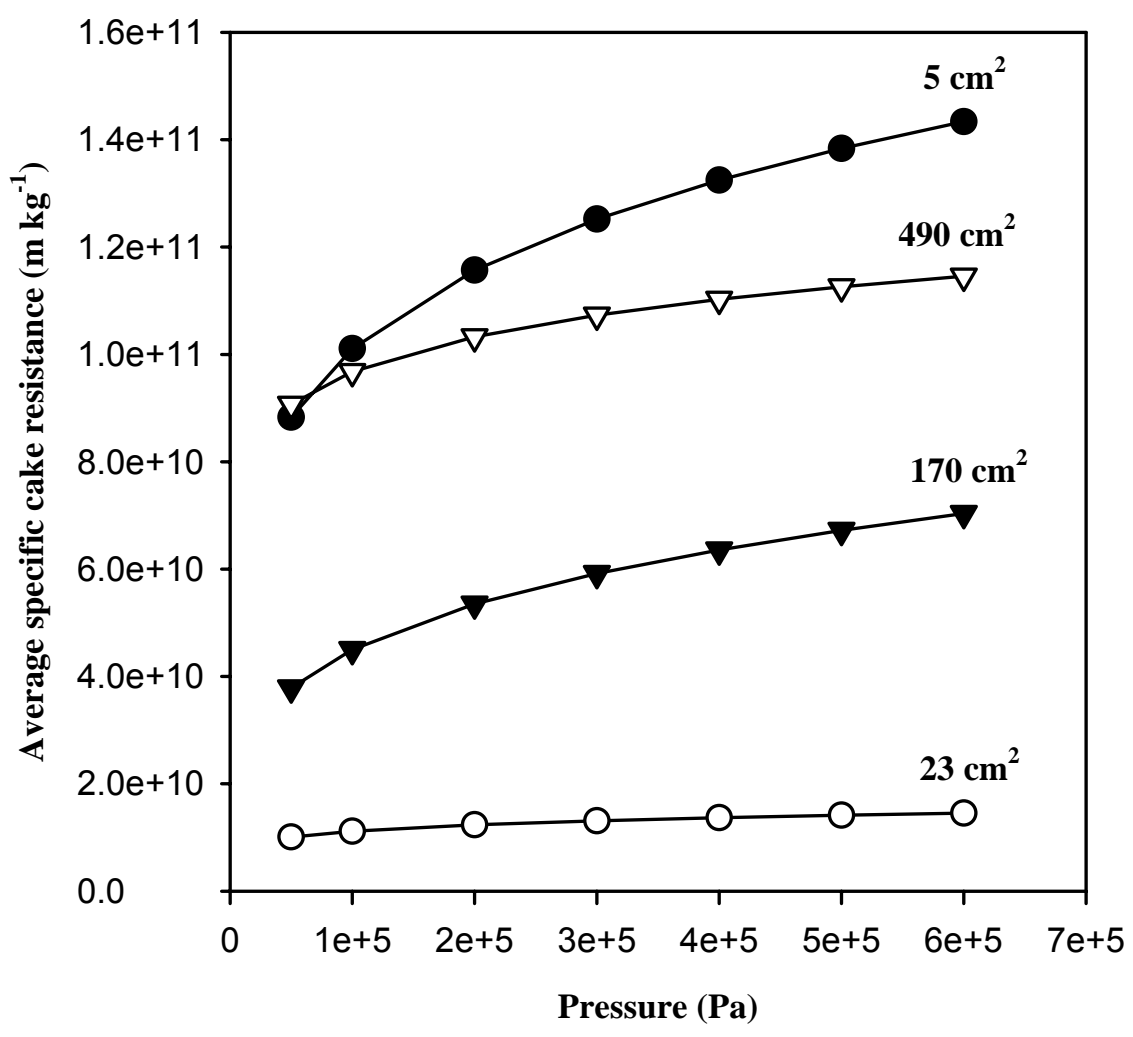

Figure 14: The influence of scale on values of specific cake resistance calculated using the scaleup constants for calcite suspensions. 


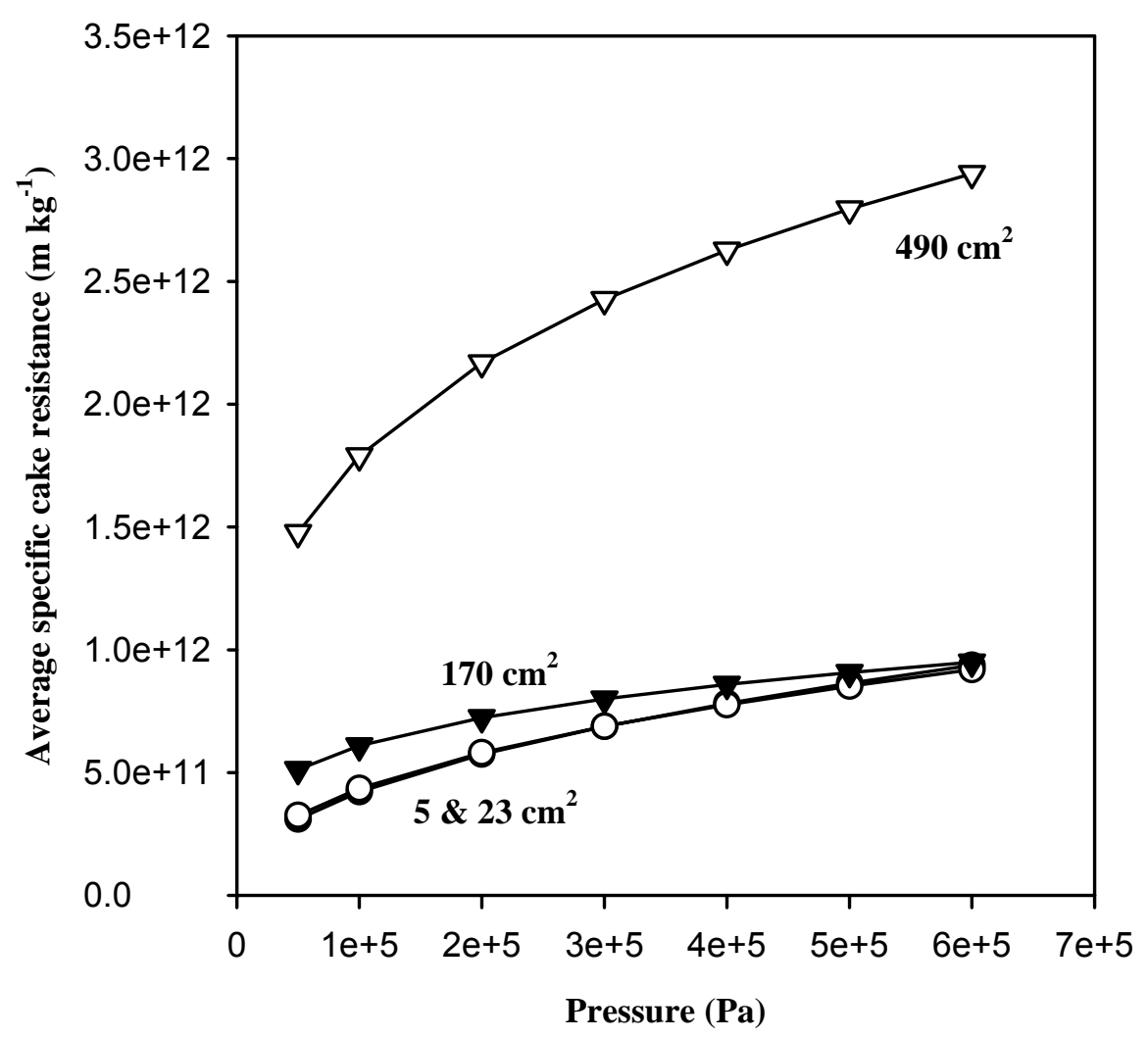

Figure 15: The influence of scale on values of specific cake resistance calculated using the scaleup constants for zinc sulphide suspensions @ $\mathrm{pH}=6.0$.

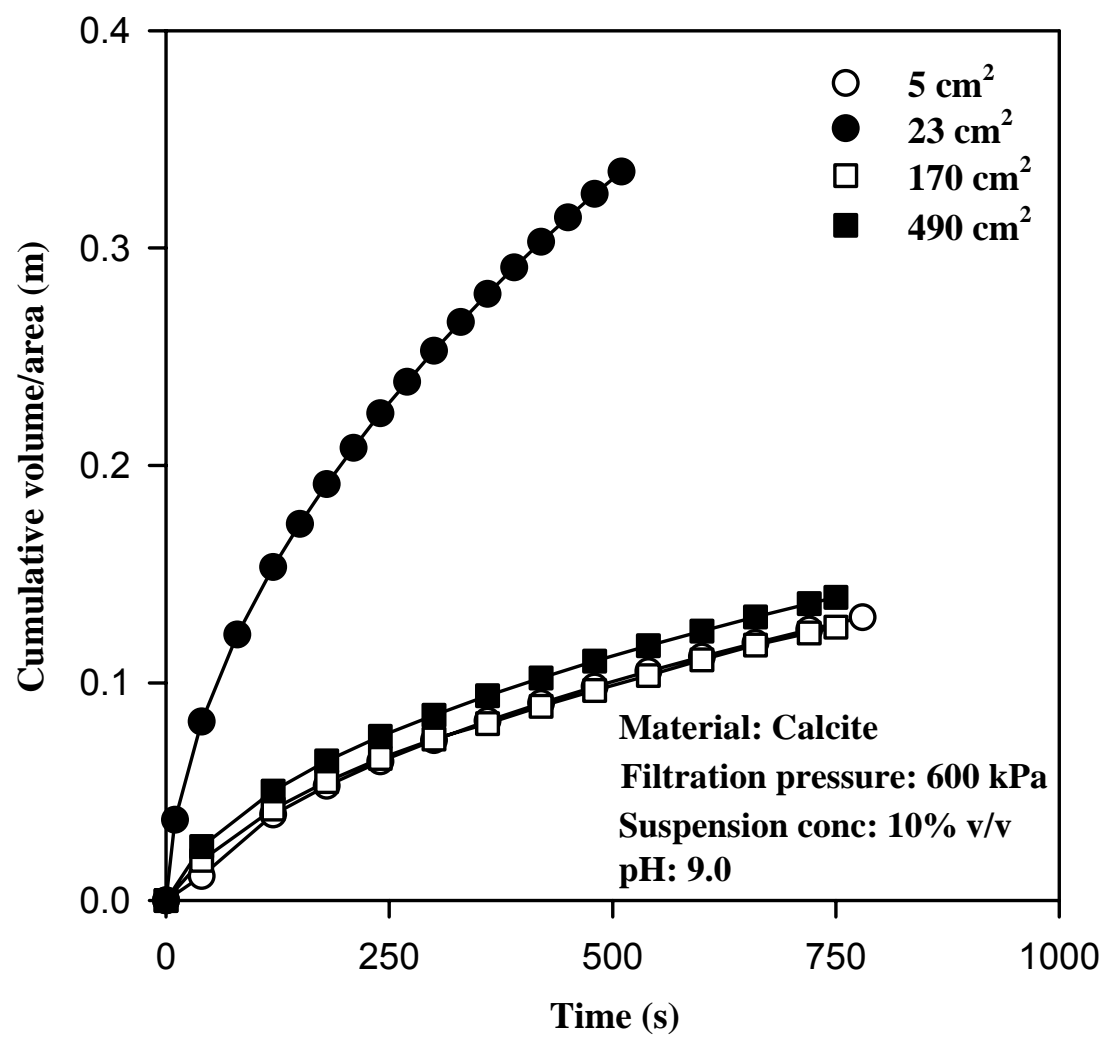

Figure 16: Influence of scale on the filtration characteristics of calcite suspensions. 


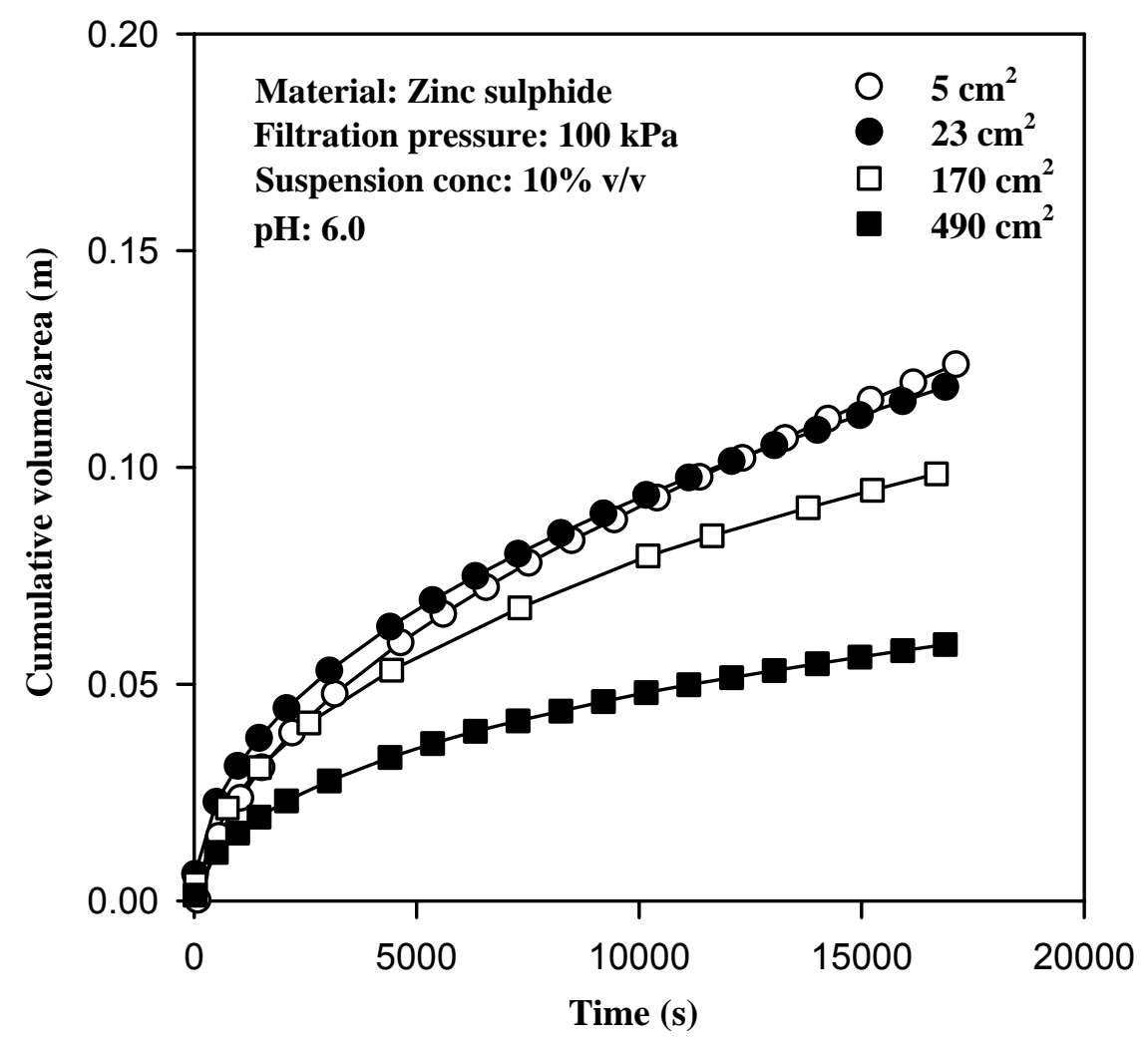

Figure 17: Influence of scale on the filtration characteristics of zinc sulphide suspensions.

\begin{tabular}{|l|c|c|c|c|}
\hline Solids & $\mathrm{pH}$ & $50 \%$ size $(\mu \mathrm{m})$ & Variance $(\mu \mathrm{m})^{2}$ & Skewness \\
\hline $\mathrm{CaCO}_{3}$ & $9.0^{*}$ & 12.77 & 213 & $1.67(\mathrm{R})$ \\
$\mathrm{ZnS}+0.1 \%$ Dispex & 2.5 & 12.44 & 3019 & $3.37(\mathrm{R})$ \\
$\mathrm{ZnS}+0.1 \%$ Dispex & $6.0^{*}$ & 15.64 & 5779 & $4.25(\mathrm{R})$ \\
$\mathrm{ZnS}+0.1 \%$ Dispex & 10.5 & 3.53 & 543 & $1.22(\mathrm{R})$ \\
\hline
\end{tabular}

$(\mathrm{R})$ denotes right handed, positive skew of the distribution; " denotes natural $\mathrm{pH}$

Table 1: Particle size data.

\begin{tabular}{|l|l|l|}
\hline Parameter examined & Calcite & Zinc sulphide \\
\hline Initial suspension concentration $(\% \mathrm{v} / \mathrm{v})$ & $5,10,20$ & 5,10 \\
Applied filtration pressure $(\mathrm{Pa})$ & $0.5 \times 10^{5}-6 \times 10^{5}$ & $0.5 \times 10^{5}-6 \times 10^{5}$ \\
Suspension $\mathrm{pH}$ & 9.0 & $2.5,6.0,10.5$ \\
Shape of particulates & Rhomboidal & Oblate ellipsoid \\
$50 \%$ size of particulates $(\mu \mathrm{m})$ & 12.8 & $3.5-15.6$ \\
Filtration area $\left(\mathrm{cm}^{2}\right)$ & $5,23,170,490$ & $5,23,170,490$ \\
\hline
\end{tabular}

Table 2: Range of conditions used in the filtration tests. 


\begin{tabular}{|c|c|c|c|c|}
\hline \multicolumn{5}{|c|}{ Calcite suspensions @ pH = 9.0} \\
\hline Filter area $\left(\mathrm{cm}^{2}\right)$ & $n(-)$ & $\alpha_{0}\left(\mathrm{~m} \mathrm{~kg}^{-1}\right)$ & $m(-)$ & $C_{0}(-)$ \\
\hline \multirow[t]{2}{*}{$\begin{array}{l}5 \\
23 \\
170 \\
490 \\
\end{array}$} & $\begin{array}{l}0.195 \\
0.147 \\
0.249 \\
0.094\end{array}$ & $\begin{array}{l}1.33 \times 10^{10} \\
2.41 \times 10^{9} \\
3.41 \times 10^{9} \\
3.62 \times 10^{10}\end{array}$ & $\begin{array}{l}0.045 \\
0.023 \\
0.004 \\
0.071\end{array}$ & $\begin{array}{l}0.218 \\
0.312 \\
0.350 \\
0.151\end{array}$ \\
\hline & $\sigma=0.057$ & $\sigma=1.36 \times 10^{10}$ & $\sigma=0.025$ & $\sigma=0.078$ \\
\hline \multicolumn{5}{|c|}{ Zinc sulphide suspensions @ pH = 2.5} \\
\hline Filter area $\left(\mathrm{cm}^{2}\right)$ & $n(-)$ & $\alpha_{0}\left(\mathrm{~m} \mathrm{~kg}^{-1}\right)$ & $m(-)$ & $C_{0}(-)$ \\
\hline \multirow[t]{2}{*}{$\begin{array}{l}5 \\
23 \\
170 \\
\end{array}$} & $\begin{array}{l}0.318 \\
0.245 \\
0.336\end{array}$ & $\begin{array}{l}5.03 \times 10^{10} \\
1.06 \times 10^{11} \\
3.20 \times 10^{10}\end{array}$ & $\begin{array}{l}0.033 \\
0.060 \\
0.107\end{array}$ & $\begin{array}{l}0.280 \\
0.191 \\
0.110\end{array}$ \\
\hline & $\sigma=0.039$ & $\sigma=3.15 \times 10^{10}$ & $\sigma=0.031$ & $\sigma=0.078$ \\
\hline \multicolumn{5}{|c|}{ Zinc sulphide suspensions @ pH =6.0 } \\
\hline Filter area $\left(\mathrm{cm}^{2}\right)$ & $n(-)$ & $\alpha_{0}\left(\mathrm{~m} \mathrm{~kg}^{-1}\right)$ & $m(-)$ & $C_{0}(-)$ \\
\hline \multirow[t]{2}{*}{$\begin{array}{l}5 \\
23 \\
170 \\
490 \\
\end{array}$} & $\begin{array}{l}0.446 \\
0.417 \\
0.248 \\
0.277\end{array}$ & $\begin{array}{l}4.48 \times 10^{9} \\
6.14 \times 10^{9} \\
4.66 \times 10^{10} \\
1.02 \times 10^{11}\end{array}$ & $\begin{array}{l}0.066 \\
0.130 \\
0.076 \\
0.050\end{array}$ & $\begin{array}{l}0.166 \\
0.077 \\
0.140 \\
0.148\end{array}$ \\
\hline & $\sigma=0.086$ & $\sigma=3.97 \times 10^{10}$ & $\sigma=0.030$ & $\sigma=0.034$ \\
\hline \multicolumn{5}{|c|}{ Zinc sulphide suspensions @ pH = 10.5} \\
\hline Filter area $\left(\mathrm{cm}^{2}\right)$ & $n(-)$ & $\alpha_{0}\left(\mathrm{~m} \mathrm{~kg}^{-1}\right)$ & $m(-)$ & $C_{0}(-)$ \\
\hline $\begin{array}{l}5 \\
23\end{array}$ & $\begin{array}{l}0.038 \\
0.015\end{array}$ & $\begin{array}{l}2.00 \times 10^{12} \\
1.72 \times 10^{12}\end{array}$ & $\begin{array}{l}0.013 \\
0.066\end{array}$ & $\begin{array}{l}0.353 \\
0.209\end{array}$ \\
\hline
\end{tabular}

Table 3: Effect of scale on scale-up 'constants' for $10 \% \mathrm{v} / \mathrm{v}$ calcite and zinc sulphide $(\triangle P$ in $\mathrm{Pa})$. 